\title{
EVALUATING MODEL UNCERTAINTY OF AN SPT-BASED SIMPLIFIED METHOD FOR RELIABILITY ANALYSIS FOR PROBABILITY OF LIQUEFACTION
}

\author{
C. HSEIN JUANG ${ }^{\text {i),ii), SUnNy Ye FAnG }}{ }^{\text {iii) }}$, Wilson H. TANG ${ }^{\text {iv), }}$, \\ Eng Hui Khor viv, Gordon Tung-Chin Kung ${ }^{\text {vi) }}$ and JiE ZHANG ${ }^{\text {vii }}$
}

\begin{abstract}
In this paper, an innovative procedure is developed for estimating the uncertainty of an empirical geotechnical model. Here, the Youd et al. (2001) method, a deterministic model for liquefaction triggering evaluation, is examined for its model uncertainty. The procedure for evaluating this model uncertainty involves two steps: 1) deriving a Bayesian mapping function based on a database of case histories, and 2) using the calibrated Bayesian mapping function as a reference to back-figure the uncertainty of the model. Details of the developed procedure within the framework of the first-order reliability method (FORM) are presented. Using FORM with the calibrated model uncertainty, the probability of liquefaction can be readily determined, and thus, the results presented in this paper extend the use of the Youd et al. (2001) method.
\end{abstract}

Key words: case history, liquefaction, model uncertainty, probability, reliability, standard penetration test (IGC: $\mathrm{D} 7 / \mathrm{E} 8)$

\section{INTRODUCTION}

This paper deals with two related problems; one is characterization and estimation of model uncertainty, the uncertainty of a given geotechnical model, and the other is reliability analysis of liquefaction potential of soils using First Order Reliability Method (FORM). Here, a new procedure is developed for estimating model uncertainty within the framework of FORM (Ang and Tang, 1984). As an example to demonstrate this new procedure, a simplified model based on Standard Penetration Test (SPT) for evaluating liquefaction potential of soils, originated by Seed and Idriss (1971) and updated by Youd et al. (2001), is examined.

The SPT-based simplified method documented in Youd et al. (2001) is generally recognized as the state-ofthe-art method for liquefaction evaluation. The Youd et al. (2001) method is a deterministic method, and liquefaction potential determined by this method is generally expressed as a factor of safety. In many occasions, however, it is desirable to determine the probability of liquefaction to account for the uncertainty in the input parameters, and in this regard, reliability analysis using FORM may be performed. A rigorous reliability analysis requires the knowledge of parameter uncertainty as well as the knowledge of model uncertainty. Once the model uncertainty of the Youd et al. (2001) method is determined, the deterministic solution obtained from this popular method can be readily extended to the probabilistic solution using the well-established FORM analysis. Thus, the results of this paper can extend the use of the Youd et al. (2001) method from a deterministic solution to both deterministic and probabilistic solutions. Furthermore, a new procedure for evaluating model uncertainty is developed in this paper, which is, by itself, a significant contribution to the theoretical side of the general reliability analysis.

Model uncertainty of a geotechnical model, particularly for those limit state models that are defined empirically, is in general difficult to determine. Phoon and Kulhawy (2005) pointed out that model uncertainty may be estimated if a sufficiently large and representative database is available. In the present study, the database of liquefaction/no-liquefaction case histories compiled and

i) Professor, Department of Civil Engineering, Clemson University, South Carolina, USA (hsein@clemson.edu).

ii) Chair Professor, Department of Civil Engineering, National Central University, Taiwan.

iii) Project Engineer, Ardaman \& Associates, FL, USA (formerly Research Assistant, Clemson University, Clemson, South Carolina, USA).

iv) Chair Professor, Department of Civil Engineering, Hong Kong University of Science and Technology, Hong Kong.

v) Technical Staff, ANSYS, Inc., Probabilistic Design and Optimization Group, PA, USA.

vi) Assistant Research Fellow, Sustainable Environment Research Center, National Cheng Kung University, Taiwan (formerly Postdoctoral Fellow, Clemson University, Clemson, South Carolina, USA).

vii) Research Assistant, Department of Civil Engineering, Hong Kong University of Science and Technology, Hong Kong.

The manuscript for this paper was received for review on July 7, 2008; approved on November $27,2008$.

Written discussions on this paper should be submitted before September 1, 2009 to the Japanese Geotechnical Society, 4-38-2, Sengoku, Bunkyo-ku, Tokyo 112-0011, Japan. Upon request the closing date may be extended one month. 
re-assessed by Cetin (2000) and Cetin et al. (2004), which include estimated statistics (mean and standard deviation) of the input parameters, is used for evaluating the model uncertainty of the Youd et al. (2001) method.

The new procedure for estimating model uncertainty involves two steps. First, a mapping function is derived by means of Bayes' theorem using a database of case histories. The mapping function allows for an interpretation of probability of liquefaction $\left(P_{\mathrm{L}}\right)$ based on a reliability index $(\beta)$ calculated from a reliability analysis using FORM that considers only parameter uncertainty, the uncertainty associated with each input variable in the limit state model. The procedure for developing such $P_{\mathrm{L}}$ $-\beta$ mapping function through a calibration with field observations was previously reported by Juang et al. (1999, 2000). In the second step, the probabilities obtained from the calibrated $P_{\mathrm{L}}-\beta$ mapping function are used as a reference to "back-figure" the uncertainty of the limit state model. This procedure for estimating model uncertainty was reported by Juang et al. (2004, 2006). Whereas the framework established by these previous studies is fundamentally sound, there is a drawback; the issue of prior probability in the development of $P_{\mathrm{L}}-\beta$ mapping function was not addressed, and possible variation in the calibrated mapping function and model uncertainty and their effects on the final probability of liquefaction were not examined. In this paper, the previous procedures are combined and refined into the new procedure.

In a simplified model for liquefaction potential evaluation such as Youd et al. (2001), the seismic loading is expressed as cyclic stress ratio (CSR) and the liquefaction resistance is expressed as cyclic resistance ratio (CRR). To measure the potential for liquefaction, factor of safety (FS), defined as the ratio of CRR over CSR, is traditionally employed. Alternatively, use of probability of liquefaction to measure liquefaction potential has also been suggested (for examples, Christian and Swiger, 1975; Liao et al., 1988; Youd and Noble, 1997; Toprak et al., 1999; Juang et al., 2002; Cetin et al., 2004). However, in the analysis of a future case using these empirical equations, uncertainties or variations in the input variables, if exist, cannot be entered into the equations (because they are not required in these equations), and thus, the obtained probability for this future case could be subject to error if the variations in the input variables are significant. To account for the variations in the input variables, a reliability analysis of soil liquefaction may be conducted (for example, Haldar and Tang, 1979). To this end, a reliability analysis to determine the probability of liquefaction using FORM is desirable.

In order to have a realistic estimate of the probability of liquefaction using FORM, it is essential to consider $e x$ plicitly both the uncertainty in the input variables and the uncertainty in the limit state model. The uncertainty in the input variables (parameters) is problem-specific, and should be evaluated by the user applying the proposed method. Nevertheless, some guidance for assessing input parameter uncertainty is provided later in this paper. On the other hand, the uncertainty in the limit state model is one main focus of this paper. Once the model uncertainty is characterized, the analysis using FORM for assessing the probability of liquefaction can be readily performed, which is another main focus of this paper.

Because the analysis using FORM has a strong theoretical basis (Ang and Tang, 1984; Baecher and Christian, 2003), the limitations of the proposed approach (technique) arise mostly from the assumptions made in the calibration of the limit state model. Thus, to apply the proposed technique to practical problems, it is essential to accommodate the following limitations:

1) To compute reliability index (Ang and Tang, 1984) using FORM, the limit state model is assumed to be linear,

2) All input random variables are assumed to be lognormally distributed,

3) No correlation is assumed between model uncertainty and input variables, and

4) The model uncertainty of the limit state model, the Youd et al. (2001) method, is calibrated using a database of liquefaction case histories compiled by Cetin et al. (2004), and as such, the proposed technique is most applicable to future cases that are similar in nature to the cases in the database.

Fortunately, the database consists of cases from many different earthquakes in different parts of the world and with a variety of soil conditions, and thusly, the proposed technique is applicable to a broad range of seismic and soil conditions. Further discussion of these limitations (assumptions) is presented later as appropriate.

\section{SPT-BASED SIMPLIFIED MODEL FOR LIQUEFCATION EVALUATION}

In this paper, the SPT-based simplified model by Youd et al. (2001) is examined for its model uncertainty. This simplified model has been, and is still, widely used for liquefaction potential evaluation in the United States and throughout much of the world. A brief summary of this model is presented to set the stage for the discussion of model uncertainty. In this method, the cyclic stress ratio (CSR) that is adjusted to reference conditions of $M_{\mathrm{w}}=7.5$ and effective stress $\sigma_{\mathrm{v}}^{\prime}=100 \mathrm{kPa}$, denoted as $\mathrm{CSR}_{7.5, \sigma}$, may be expressed as (this form is modified slightly from the original form by Seed and Idriss, 1971; the modified form has appeared previously in Juang et al., 2002; Idriss and Boulanger, 2004; Juang et al., 2006; see additional discussion presented later):

$$
\mathrm{CSR}_{7.5, \sigma}=0.65\left(\frac{\sigma_{\mathrm{v}}}{\sigma_{\mathrm{v}}^{\prime}}\right)\left(\frac{a_{\mathrm{max}}}{g}\right)\left(r_{\mathrm{d}}\right) / \mathrm{MSF} / K_{\sigma}
$$

where $\sigma_{\mathrm{v}}=$ the total overburden stress at the depth of interest $(\mathrm{kPa}), \sigma_{\mathrm{v}}^{\prime}=$ the effective stress at the depth of interest $(\mathrm{kPa}), g=$ the unit of the acceleration of gravity, $a_{\text {max }}=$ the peak horizontal ground surface acceleration ( $a_{\max } / g$ is dimensionless), $r_{\mathrm{d}}=$ the depth-dependent stress reduction factor (dimensionless), $\mathrm{MSF}=$ the magnitude scaling factor (dimensionless), and $K_{\sigma}=$ the overburden stress adjustment factor for the calculated CSR (dimen- 
sionless). The parameter $r_{\mathrm{d}}$ is a function of depth where cyclic stress ratio is calculated, the parameter MSF is a function of moment magnitude $M_{\mathrm{w}}$, and the parameter $K_{\sigma}$ is a function of the effective stress $\sigma_{\mathrm{v}}^{\prime}$. For $a_{\mathrm{max}}$, the geometric mean is preferred for use in engineering practice, although use of the larger of the two orthogonal peak accelerations is conservative and allowable (Youd et al., 2001).

For routine practice and no critical projects, the following equations may be used to estimate the values of $r_{\mathrm{d}}$ (Liao and Whitman, 1986; Youd et al., 2001):

$$
\begin{array}{ll}
r_{\mathrm{d}}=1.0-0.00765 d & \text { for } d<9.15 \mathrm{~m}, \\
r_{\mathrm{d}}=1.174-0.0267 d & \text { for } 9.15 \mathrm{~m}<d \leq 20 \mathrm{~m}
\end{array}
$$

where $d=$ the depth of interest $(\mathrm{m})$. The variable MSF may be calculated with the following equation (Youd et al., 2001):

$$
\mathrm{MSF}=\left(M_{\mathrm{w}} / 7.5\right)^{-2.56}
$$

It should be noted that different formulas for $r_{\mathrm{d}}$ and MSF have been proposed by many investigators (e.g., Youd et al., 2001; Idriss and Boulanger, 2004; Cetin et al., 2004). To be consistent with the Youd et al. (2001) method, use of Eqs. (2) and (3) is required.

As noted previously, the variable $K_{\sigma}$ is a stress adjustment factor used to adjust CSR to the effective overburden stress of $\sigma_{\mathrm{v}}^{\prime}=100 \mathrm{kPa}$. This is different from the overburden stress correction factor $\left(C_{\mathrm{N}}\right)$ that is applied to the SPT blow count $\left(N_{60}\right)$, which is described later. The adjustment factor $K_{\sigma}$ is defined as follows (Hynes and Olsen, 1999; Youd et al., 2001):

$$
K_{\sigma}=\left(\sigma_{\mathrm{v}}^{\prime} / P_{\mathrm{a}}\right)^{(f-1)}
$$

where $f \approx 0.6$ to 0.8 . For routine practice and no critical projects, $f=0.7$ may be assumed, and thus, the exponent in Eq. (4) would be -0.3 .

Finally, it should be noted that in the formulation of the Youd et al. (2001) method, the factors MSF and $K_{\sigma}$ were applied to the term cyclic resistance ratio (CRR). In other words, CRR was multiplied by the term $K_{\sigma}$ and the term MSF (both as a multiplier) before comparing with CSR. In this paper, however, both $K_{\sigma}$ and MSF are applied to the original CSR as a divisor, as shown in Eq. (1), and the corrected CSR, in terms of $\mathrm{CSR}_{7.5, \sigma}$, is then compared with CRR for assessing liquefaction potential. The two approaches have the same effect but Eq. (1) is preferred (Juang et al., 2002; Idriss and Boulanger 2004; Juang et al., 2006) because it is desirable to lump the effect of MSF and $K_{\sigma}$ with seismic load parameters and overburden pressures so that the term CRR would only be dependent on corrected SPT blow count.

For the convenience of presentation hereinafter, the adjusted cyclic stress ratio $\mathrm{CSR}_{7.5, \sigma}$ is simply labeled as CSR whenever no confusion would be caused by such use. For liquefaction potential evaluation, CSR is compared with cyclic resistance ratio (CRR). In the SPTbased model by Youd et al. (2001), the CRR is calculated as:

$$
\mathrm{CRR}=\frac{1}{34-N_{1,60 \mathrm{cs}}}+\frac{N_{1,60 \mathrm{cs}}}{135}+\frac{50}{\left[10 \cdot N_{1,60 \mathrm{cs}}+45\right]^{2}}-\frac{1}{200}
$$

where $N_{1,60 \text { cs }}$ (dimensionless) is the clean-sand equivalence of the overburden stress-corrected SPT blow count, defined as (Youd et al., 2001):

$$
N_{1,60 \mathrm{cs}}=\alpha+\beta N_{1,60}
$$

where $\alpha$ and $\beta$ are coefficients to account for the effect of fines content (FC) and both are a function of FC; and $N_{1,60}$ is the SPT blow count normalized to the reference hammer energy efficiency of $60 \%$ and effective overburden stress of $100 \mathrm{kPa}$ :

$$
N_{1,60}=C_{\mathrm{N}} N_{60}
$$

where $N_{60}=$ the SPT blow count at 60 percent hammer energy efficiency and corrected for rod length, sampler configuration, and borehole diameter (Skempton, 1986; Youd et al., 2001) and

$$
C_{\mathrm{N}}=\left(P_{\mathrm{a}} / \sigma_{\mathrm{v}}^{\prime}\right)^{0.5} \leq 1.7
$$

where $P_{\mathrm{a}}=$ atmosphere pressure $(\approx 100 \mathrm{kPa})$. The coefficients, $\alpha$ and $\beta$, in Eq. (6) are related to fines content (FC) as follows (Youd et al., 2001):

$$
\begin{aligned}
\alpha & =0 \text { for } \mathrm{FC} \leq 5 \% \\
& =\exp \left[1.76-\left(190 / \mathrm{FC}^{2}\right)\right] \text { for } 5 \%<\mathrm{FC}<35 \% \\
& =5.0 \text { for } \mathrm{FC} \geq 35 \% \\
\beta & =1.0 \text { for } \mathrm{FC} \leq 5 \% \\
& =[0.99+(\mathrm{FC} 1.5 / 1000)] \text { for } 5 \%<\mathrm{FC}<35 \% \\
& =1.2 \text { for } \mathrm{FC} \geq 35 \%
\end{aligned}
$$

In reference to CSR defined in Eq. (1), the equation for CRR (Eq. (5)) defines the boundary curve in a two-dimensional liquefaction evaluation chart. In the deterministic approach, factor of safety (FS), defined as $\mathrm{FS}=$ CRR/CSR, is used to measure liquefaction potential. In theory, liquefaction is said to occur if $\mathrm{FS} \leq 1$, and no liquefaction if FS $>1$. The entire process of determining CSR, CRR, and FS through the use of Eqs. (1) through (10) is the SPT-based deterministic model adopted in this paper. This set of equations collectively is referred to as the modified Youd et al. (2001) model. The modification to the original Youd et al. (2001) method is very minor and the two methods yield the same factor of safety for any given case. Nevertheless, the two do not have exactly the same formulation, and to avoid the unnecessary confusion, this deterministic model is referred to as the modified Youd et al. (2001) model.

As noted previously, the Youd et al. (2001) model is widely used. However, it was created by a large group of experts in a liquefaction workshop (Youd et al., 1997) with diverse opinions. The uncertainty of this model was never evaluated, and thus, it should be of significant contribution to evaluate the model uncertainty of this model. In the sections that follow, the model uncertainty of the modified Youd et al. (2001) model is evaluated, and the reliability analysis using the calibrated model uncertainty is presented and discussed. 


\section{PROCEDURE FOR EVALUATING MODEL UNCERTAINTY}

In the context of reliability analysis, the liquefaction boundary curve may be taken as a limit state. According to Juang et al. (2006), the limit state model of liquefaction triggering may be expressed as:

$$
h(\mathbf{x})=c^{*} \mathrm{CRR}-\mathrm{CSR}=0
$$

where $\mathbf{x}$ is a vector of input variables that consist of soil and seismic parameters that are required in the calculation of CRR and CSR (Eqs. (1) through (10)), and $h(\mathbf{x})<0$ indicates liquefaction. The random variable $c$ is employed to describe the model uncertainty of the limit state model. Use of a single random variable to describe the model uncertainty is appropriate because the only data available for calibration is in the form of binary field observation of liquefaction or no liquefaction. The random variable $c$ is referred to herein as the model uncertainty factor, or simply model factor. The reader is referred to Ang and Tang (1984) and Juang et al. (2006) for background and use of a model factor to characterize the model uncertainty.

It should be noted that while the form of Eq. (11) appears to be simple at the first glance, the formulations of CSR and CRR are highly nonlinear, and thus, the function $h(\mathbf{x})$ is actually highly nonlinear with respect to the basic input variables that are required in the calculations of CSR and CRR. In the subsequent reliability analysis using FORM, these basic variables and their correlations are considered directly in the analysis.

The ultimate goal of this paper is to present a procedure for determining the probability of liquefaction using the well-established reliability method. The foundation of such reliability analysis is the knowledge of the model uncertainty of the adopted limit state model (in this paper, it is the modified Youd et al. model, represented collectively by Eqs. (1) through (10)). To begin with, the variables of the limit state model, those that are required for the calculation of CSR and CRR, are first discussed.

\section{Random Variables in the Modified Youd et al. (2001) Model}

CSR expressed in Eq. (1) is a function of $a_{\max }, M_{\mathrm{w}}, \sigma_{\mathrm{v}}^{\prime}$, $\sigma_{\mathrm{v}}$, and $r_{\mathrm{d}}$, since MSF is a function of $M_{\mathrm{w}}$ and $K_{\sigma}$ is a function of $\sigma_{\mathrm{v}}^{\prime}$ as noted previously. The first four variables, $a_{\max }, M_{\mathrm{w}}, \sigma_{\mathrm{v}}^{\prime}$, and $\sigma_{\mathrm{v}}$ are assumed to be random variables in the reliability analysis to be presented. Selection of $a_{\text {max }}, M_{\text {w }}$ as a random variable is obvious; they account for the uncertainty in the seismic loading. Selection of the variables $\sigma_{\mathrm{v}}^{\prime}$ and $\sigma_{\mathrm{v}}$ as a random variable is to account for the possible uncertainty in the unit weight of soil and the depth of ground water table. The variable $r_{\mathrm{d}}$ is a derived parameter that is a function of depth (Eq. (2)). Although the depth to liquefiable layer (see Eq. (2)) in a particular case is not necessary a "certain" value, CSR and CRR in the modified Youd et al. (2001) model are evaluated for the soil at the same given depth, and thus, the variable $r_{\mathrm{d}}$ may be treated as a non-random variable. Of course, there is significant uncertainty in the value of $r_{\mathrm{d}}$ determined from Eq. (2). Similarly, there is significant uncertainty in the value of MSF and $K_{\sigma}$ determined from Eqs. (3) and (4), respectively. These are the uncertainties of the "component" models, as Eqs. (2), (3), and (4) are the integral part of the modified Youd et al. (2001) model. The uncertainty in the component models (Eqs. (2), (3), and (4)) is eventually reflected in the uncertainty of the entire model, and thus, in this paper, only the model uncertainty of the entire modified Youd model is to be calibrated. Although it may not be ideal to lump the uncertainties of the component models into the uncertainty of the entire modified Youd model, it is a necessity as the only data that are available for model calibration are the binary field observations (liquefaction or no liquefaction) that reflect the combined effects of CSR and CRR.

Through similar reasoning, the variation in the CRR determined from Eq. (5) and the associated equations (Eqs. (6) through (10)) may be attributed to two random variables, $N_{1,60}$ and FC. Again, the uncertainty in the component models (Eqs. (6) through (10)) is not calibrated separately; rather, they are considered integral part of the modified Youd et al. (2001) model.

Based on the above discussions, a total of six random variables, including $N_{1,60}, \mathrm{FC}, M_{\mathrm{w}}, a_{\max }, \sigma_{\mathrm{v}}^{\prime}$, and $\sigma_{\mathrm{v}}$, are identified in the modified Youd et al. (2001) model. The uncertainties in these variables, referred to as "parameter uncertainties," are an essential element in a reliability analysis and must be fully addressed. In this paper, these variables are assumed to be lognormally distributed random variables, although other distribution such as normal distribution may also be used. The use of lognormal distribution is based on two aspects: first, the measured geotechnical parameters are often modeled well with lognormal distribution (Jefferies et al., 1988); and second, the lognormal distribution prevents negative parameter values. Previous study (Juang et al., 2000) has shown that the difference between the results of using the lognormal distribution versus the normal distribution in the reliability analysis is quite modest. Furthermore, even with this possible difference, the "induced" error, if any, can be considered as an integral part of the model uncertainty of the entire modified Youd model.

Based on the above discussion of the random variables of the modified Youd model, the limit state defined in Eq. (11) may be re-written as follows:

$$
\begin{aligned}
h(\mathbf{x}) & =c^{*} \mathrm{CRR}-\mathrm{CSR} \\
& =h\left(c, N_{1,60}, \mathrm{FC}, M_{\mathrm{w}}, a_{\max }, \sigma_{\mathrm{v}}^{\prime}, \sigma_{\mathrm{v}}\right)=0
\end{aligned}
$$

\section{Procedure for Estimating Model Factor}

The earlier version of the procedure for estimating or calibrating model factor in a limit state model such as Eq. (12) has previously described by Juang et al. (2006). A brief summary is provided in the following. The premise of this procedure is that the probability of liquefaction can be inferred from observed ground performances without the knowledge of model uncertainty. In this regard, Juang et al. (1999) showed that a mapping-func- 
tion that relates the probability of liquefaction $\left(P_{\mathrm{L}}\right)$ to reliability index $(\beta)$ can be established by applying Bayes' theorem to observed performance data:

$$
P_{\mathrm{L}}=P(L \mid \beta)=\frac{P(\beta \mid L) P(L)}{P(\beta \mid L) P(L)+P(\beta \mid N L) P(N L)}
$$

where $P(L \mid \beta)=$ probability of liquefaction for a given $\beta$; $P(\beta \mid L)=$ probability of $\beta$, given that liquefaction did occur; $P(\beta \mid N L)=$ probability of $\beta$, given that liquefaction did not occur; $P(L)=$ prior probability of liquefaction; $P(N L)=$ prior probability of no-liquefaction.

It should be noted that "sample bias" (i.e., the bias in a sample or database where the number of liquefied cases is greater than the number of non-liquefied cases because of choice in sampling; for example, see Liao et al., 1988) is not an issue in the derived mapping function. The two conditional probability functions, $P(\beta \mid L)$ and $P(\beta \mid N L)$, are derived using liquefied data subset and non-liquefied data subset separately. These functions are equally applicable to the population of sites analyzed. Estimation of the prior probabilities, $P(L)$ and $P(N L)$, however, is a different story. The latter, estimation of the prior probabilities, is a challenging issue, which is a key element of this paper and is discussed later.

To derive the $P_{\mathrm{L}}-\beta$ mapping function based on Eq. (13), reliability analyses are performed for all cases in the data set assuming that the model factor is a constant, $c=$ 1. In other words, reliability analyses are performed considering only the parameter uncertainty as the model uncertainty is assumed to be non-existent. This assumption is out of necessity because at this point, the knowledge (or more precisely, statistical characterization) of model factor $c$ is not available. Even though the reliability index $\beta$ is calculated without the knowledge of the model factor, the probability of liquefaction inferred for a given $\beta$ based on the developed $P_{\mathrm{L}}-\beta$ mapping function is considered an adequate approximation of the "true" probability because the mapping function is calibrated for this very definition of $\beta$ using observed ground performance data.

For convenience of presentation, the reliability index calculated with the assumption that the model factor is a constant, $c=1$, is hereinafter denoted as $\beta_{1}$. For this $\beta_{1}$, the probability of liquefaction is inferred from the developed Bayesian mapping function, rather than from the nominal concept (i.e., $P_{\mathrm{L}}=1-\Phi\left(\beta_{1}\right)$ where $\Phi$ is the cumulative standard normal distribution function). The probability inferred from the Bayesian mapping function with a given $\beta_{1}$, denoted as $P_{\mathrm{L} 1}$, is considered accurate, as reasoned previously, while the probability based on the nominal concept might be subject to error if the "correct" model uncertainty is not included in the reliability analysis. If the model factor is known (i.e., with adequate statistical characterization) and incorporated in the reliability analysis, the calculated reliability index, denoted as $\beta_{3}$, and the corresponding nominal probability, denoted as $P_{\mathrm{L} 3}$, will be accurate theoretically.

Under the premise that the probability of liquefaction can be inferred from observed ground performance, the probability of liquefaction $P_{\mathrm{L} 1}$ inferred from the Bayesian mapping function can then be used as a reference for estimation or calibration of the model factor. The idea of this calibration is to find a set of statistical parameters (for example, the mean and standard deviation) of the model factor $c$ such that the nominal probability $P_{\mathrm{L} 3} \mathrm{ob}-$ tained from the FORM analysis matches the probability $P_{\mathrm{L} 1}$ inferred from the Bayesian mapping function that has been calibrated with observed performance data. To implement this idea, each of the 201 cases in the data set is analyzed for $P_{\mathrm{L} 1}$ (through a reliability analysis for $\beta_{1}$ with an assumption that $c=$ constant $=1$ ) and $P_{\mathrm{L} 3}$ (through a reliability analysis for $\beta_{3}$ with an assumption that $c=$ an undetermined random variable). By means of a trial-anderror process with varying statistical parameters, the model factor in Eq. (12) can be estimated based on minimization of the root-mean-square-error (RMSE) defined below:

$$
\mathrm{RMSE}=\sqrt{\frac{\sum_{i=1}^{N}\left(P_{\mathrm{L} 3}-P_{\mathrm{L} 1}\right)^{2}}{N}}
$$

where $N$ is the number of cases in the data set (in this study, $N=201$ ).

In this paper, the above procedure is applied to estimating the model uncertainty of the modified Youd et al. (2001) model. An improvement on this procedure is made to better characterize the prior probability in Eq. (13). The effect of the variation of the Bayesian mapping function on the estimated model factor is also investigated. Once fully calibrated, the model factor can be used along with the knowledge of parameter uncertainties in the reliability analysis of a future case, and the accurate nominal probability of liquefaction can be determined with a routine reliability analysis that can be easily implemented in a spreadsheet.

\section{MODEL FACTOR CALIBRATED BASED ON PERFORMANCE DATA}

\section{Database of Liquefaction Case Histories}

The source of liquefaction/no-liquefaction case histories used in the present study was compiled and documented by Cetin (2000), which was later reported in Cetin et al. (2004). Cetin (2000) examined a large collection of liquefaction/no-liquefaction case histories from published and unpublished records. His final database consisted of 201 cases ( 89 non-liquefied cases and 112 liquefied cases; note that 3 marginal liquefaction cases were treated as liquefied cases herein). These cases were derived from earthquakes from different parts of the world. The soils in these case histories ranged from clean gravels and sands to silt mixtures (sandy and clayey silts). The depths at which the cases were reported ranged from $1.05 \mathrm{~m}$ to $20.5 \mathrm{~m}$. The corrected SPT blow count $N_{1,60}$ ranged from 2 to 64.3 , and the fines content in percent ranged from 0 to 92 . The vertical effective and total stresses $\sigma_{\mathrm{v}}^{\prime}$ and $\sigma_{\mathrm{v}}$ in $\mathrm{kPa}$ were in the ranges of 8 to 199 , and 15.5 to 384 , respectively. The peak horizontal ground 
surface acceleration $a_{\max }$ ranged from $0.09 \mathrm{~g}$ to $0.7 \mathrm{~g}$. The earthquake's moment magnitude $M_{\mathrm{w}}$ ranged from 5.9 to 8.0 .

\section{Model Uncertainties and Correlations among Input Vari- ables}

In the reliability analysis presented herein, the input random variables are assumed to follow a lognormal distribution, as noted previously. A lognormal distribution requires knowledge of the mean and standard deviation. For each case history in the database, both the mean and the standard deviation (or the coefficients of variation) are available; they were estimated by Cetin (2000) based on limited field data. The reader is referred to Cetin (2000) for additional detail of these case histories and parameter variations.

It is noted that the correlations among the six input random variables are also incorporated in the reliability analysis in the present study. To deal with correlated lognormally distributed random variables, the equivalent normal variables are first obtained, followed by a transformation to the uncorrelated normal space. The reader is referred to the literature (e.g., Der Kiureghian and Liu, 1985; Haldar and Mahadevan, 2000) for details regarding the treatment of correlated non-normal random variables in the FORM analysis.

The correlation coefficients may be estimated empirically using statistical methods. Except for the pair of $a_{\max }$ and $M_{\mathrm{w}}$, the correlation coefficient between each pair of variables used in the limit state model is estimated based on an analysis of the actual data in the database. The correlation coefficient between $a_{\mathrm{max}}$ and $M_{\mathrm{w}}$ is taken to be 0.9 , which is based on statistical analysis of the simulated data generated from the attenuation relationships (Juang et al., 1999). This correlation is suitable for back-analysis of case histories where $a_{\max }$ is obtained through the attenuation relationship established for a given earthquake $\left(M_{\mathrm{w}}\right)$. In a forward analysis of a future case subject to uncertain sources, this correlation could be much lower, and thus lower correlation coefficient should be used accordingly. The coefficients of correlation among the six input variables are shown in Table 1. These values are considered appropriate for back-analysis of the case histories in the database.

Although the details are not shown herein, a series of sensitivity analyses were carried out to examine the effect of varying the coefficients of correlation of these pairs (for example, the coefficient of correlation between $a_{\max }$ and $M_{\mathrm{w}}, \rho_{a_{\max }, M_{\mathrm{w}}}=0.6$ instead of 0.9 ; the coefficient of correlation between $N_{1,60}$ and $\sigma_{\mathrm{v}}^{\prime}, \rho_{N_{1,60}, \sigma_{v}^{\prime}}=0.5$ instead of 0.3 ). Based on the results of reliability analyses of 201 cases in the database, the difference in the calculated reliability in$\operatorname{dex} \beta$ between $\rho_{N_{1,60}, \sigma_{v}^{\prime}}=0.5$ and 0.3 is about $1 \%$ and the resulting difference in the calculated probabilities, in terms of root-mean-square error (RMSE), is 0.002. Similarly, based on the results of reliability analyses of 201 cases in the database, the difference in the calculated reliability index $\beta$ between $\rho_{a_{\max }, M_{\mathrm{w}}}=0.6$ and 0.9 is about $6 \%$ and the resulting difference in the calculated probabili-
Table 1. Coefficients of correlation among the six input variables (after Juang et al., 1999, 2008b)

\begin{tabular}{c|c|c|c|c|c|c}
\hline Variable Variable & $N_{160}$ & $F_{\mathrm{C}}$ & $\sigma_{\mathrm{v}}^{\prime}$ & $\sigma_{\mathrm{v}}$ & $a_{\max }$ & $M_{\mathrm{w}}$ \\
\hline$N_{160}$ & 1 & 0 & 0.3 & 0.3 & 0 & 0 \\
\hline$F_{\mathrm{C}}$ & 0 & 1 & 0 & 0 & 0 & 0 \\
\hline$\sigma_{\mathrm{v}}^{\prime}$ & 0.3 & 0 & 1 & 0.9 & 0 & 0 \\
\hline$\sigma_{\mathrm{v}}$ & 0.3 & 0 & 0.9 & 1 & 0 & 0 \\
\hline$a_{\max }$ & 0 & 0 & 0 & 0 & 1 & $0.9^{(1)}$ \\
\hline$M_{\mathrm{w}}$ & 0 & 0 & 0 & 0 & $0.9^{(1)}$ & 1 \\
\hline
\end{tabular}

${ }^{(1)}$ This is estimated based on local attenuation relationships calibrated to given historic earthquakes (Juang et al., 1999). This is suitable for reliability analysis of a case history, as in the post-event investigation. The correlation of these two parameters at a locality subjected to uncertain sources, as in the analysis of a future case, could be much lower and even negligible. In such cases, the joint distribution of $a_{\max }$ and $M_{\mathrm{w}}$ may be developed (Juang et al., 2008a), which can provide a more accurate estimate of the correlation.

ties, in terms of RMSE, is 0.011. These differences are considered relatively insignificant since they are within the "precision" of the procedure for the model factor calibration.

It should be noted that the correlation matrix as shown in Table 1 must be symmetric and "positive definite", (Phoon, 2004). If this condition is not satisfied, a negative variance might be obtained, which would contradict the definition of the variance. For the correlation matrix shown in Table 1, the diagonal entries of the matrix of Cholesky factors are all positive; thus, the condition of " "positive definiteness" is satisfied.

The model factor, which is a random variable, is often assumed to follow lognormal distribution (e.g., Phoon and Kulhawy, 2005; Juang et al., 2006). Although the model factor may also be assumed to follow normal distribution, use of lognormal distribution is preferred in this study because all other input variables are also modeled with lognormal distribution, which makes it easier to code the FORM procedure. Use of lognormal distribution also avoids, in theory, any possibility of a negative model factor. Furthermore, the variation in the calculated reliability index caused by the assumed distribution of model factor is eventually reflected in the model factor that is calibrated with observed performance data. With the assumption of lognormal distribution, the characterization of this model factor $c$ is thus reduced to the task of determining the mean $\mu_{\mathrm{c}}$ and standard deviation $\sigma_{\mathrm{c}}$ (or its coefficient of variation).

For reliability analysis using FORM in this study, no correlation is assumed between the model factor $c$ and each of the input variables in Eq. (12). This assumption is deemed appropriate because: (1) the only data available for model calibration is the binary field observations of liquefaction or no-liquefaction and thus, the model factor should "operate" only at this level of detail, and (2) even if some degree of correlation does exist (e.g., Phoon and Kulhawy (2005) and Phoon et al. (2006) reported weak to 
moderate correlations in their analyses of observed capacities of foundations), the effect of not incorporating such correlation in the reliability analysis would have been "compensated" in the calibration process and reflected in the calibrated model factor. In other words, the assumption of "zero correlation"' between model factor $c$ and other six input variables may be considered as part of the entire model, and the error, if any, as a result of this assumption will be reflected in the model uncertainty of the entire model.

Reliability Analysis, Bayesian Mapping Function, and Inferred Model Factor

For each case in the data set of 201 cases, the FORM analysis based on the adopted limits state model (Eq. (12) and all the associated equations, Eqs. (1) through (10)) is first conducted considering parameter uncertainties but not model uncertainty, and a reliability index $\beta_{1}$ is obtained. Repeating this analysis for all 201 cases, and then applying Eq. (13), the following $P_{\mathrm{L}}-\beta_{1}$ mapping function is obtained under the assumption that prior probabilities, $P(L)=P(N L)$ :

$$
P_{\mathrm{L}}=\frac{1}{1+a \exp \left[b \beta_{1}\right]}
$$

where $a=0.67$ and $b=1.89$ are the curve-fitting coefficients $\left(R^{2}=0.95\right.$ for this least-square regression). It should be noted that the $\beta_{1}$ (reliability index) computed for all cases in the database range from -3.95 to 4.90 ; thus, practically Eq. (15) is applicable to all cases, as the $\beta_{1}$ values in this range corresponds to the probabilities ranging from 0 to 1 .

It is noted that the prior probabilities, $P(L)$ and $P(N L)$, are difficult to determine, and when there is no prior information, the assumption of $P(L)=P(N L)$ is not unreasonable. The scenario of $P(L) \neq P(N L)$ is examined later. Using the developed mapping function, the conditional probability of liquefaction for a given $\beta_{1}$ can be inferred. Thus, the reference probability $\left(P_{\mathrm{L} 1}\right)$ for each of the 201 cases is obtained. These reference probabilities can be used to back-figure the model factor, as outlined previously.

As reported in the previous work (Juang et al., 2006), the effect of the variation of $\mathrm{COV}_{-}$, the coefficient of variation of model factor $c$, on the final probability $\left(P_{\mathrm{L} 3}\right)$ obtained from the FORM analysis is relatively small compared to the effect of the variation of the mean of model factor $\left(\mu_{\mathrm{c}}\right)$ on the final probability. To re-confirm this result, a series of sensitivity analysis is performed in this study. First, for each of the 201 cases, the FORM analysis is performed assuming each of the four scenarios: (a) $\mu_{\mathrm{c}}=$ 1.0 and $\mathrm{COV}_{-\mathrm{c}}=0.0$, (b) $\mu_{\mathrm{c}}=1.0$ and $\mathrm{COV}_{-\mathrm{c}}=0.1$, (c) $\mu_{\mathrm{c}}$ $=1.0$ and $\mathrm{COV}_{-\mathrm{c}}=0.2$, and (d) $\mu_{\mathrm{c}}=1.0$ and $\mathrm{COV}_{-\mathrm{c}}=0.3$. Under each scenario, the reliability analysis is repeated for all 201 cases, and the difference between the nominal probabilities $\left(P_{\mathrm{L} 3}\right)$ obtained from the FORM analysis and the Bayesian probabilities $\left(P_{\mathrm{L} 1}\right)$ obtained from Eq. (15), in terms of RMSE as defined in Eq. (14), is calculated. Figure 1 shows the calculated RMSE values for the four

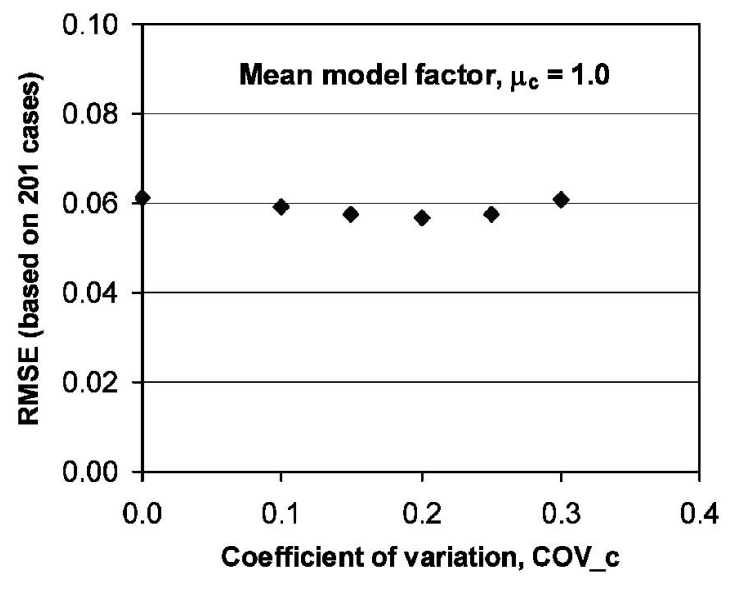

Fig. 1. The effect of the COV component of the model factor on the nominal probabilities determined through the FORM analysis

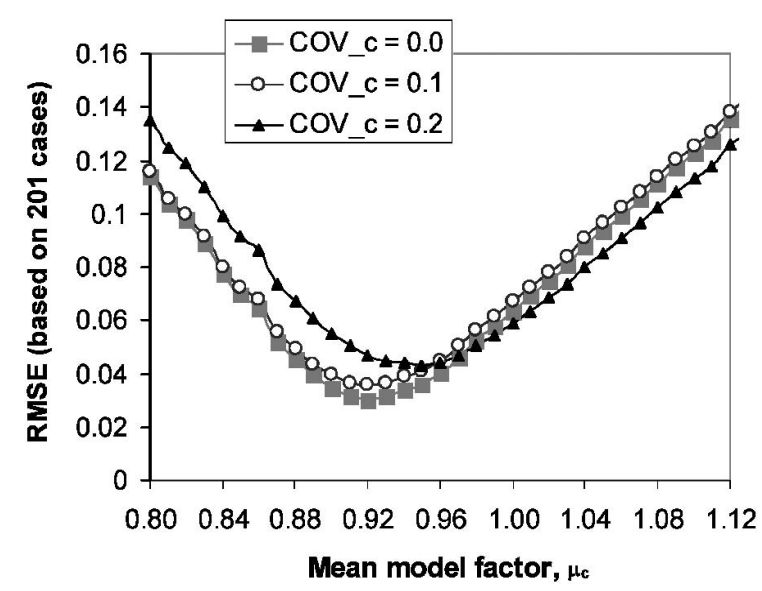

Fig. 2. Optimum mean model factors calibrated with different assumed COVs

scenarios. The results re-confirm that the effect of the variation of $\mathrm{COV}_{-c}$ on the final probability $\left(P_{\mathrm{L} 3}\right)$ obtained from the FORM analysis is relatively insignificant, although the minimum RMSE occurs approximately at $\mathrm{COV}_{-\mathrm{c}}=0.2$. Thus, in the subsequent analysis for the mean model factor, $\mathrm{COV}_{\text {_c }}$ may be assumed to be 0 without incurring much error.

For the adopted limit state model (the modified Youd et al. model), the mean of the model factor is determined to be $\mu_{\mathrm{c}}=0.92$ under the assumption of $\mathrm{COV}_{-\mathrm{c}}=0$. To further investigate the effect of $\mathrm{COV}_{-c}$, the analysis is repeated for the scenarios of $\mathrm{COV}_{-\mathrm{c}}=0.1$ and 0.2 (recalling that the optimum $\mathrm{COV}_{-c}$ is approximately at 0.2 ). Under the assumption of $\mathrm{COV}_{-\mathrm{c}}=0.1$, the optimum $\mu_{\mathrm{c}}$ is determined to be 0.93 , and under the assumption of $\mathrm{COV}_{\text {c }}=0.2$, the optimum $\mu_{\mathrm{c}}$ is determined to be 0.94 . The results of these analyses are shown in Fig. 2. To see the difference among the nominal probabilities $\left(P_{\mathrm{L} 3}\right)$ obtained through the FORM analysis incorporating these three characterizations of model factor, (a) $\mu_{\mathrm{c}}=0.92$ and $\mathrm{COV}_{-\mathrm{c}}=0.0$, (b) $\mu_{\mathrm{c}}=0.93$ and $\mathrm{COV}_{-\mathrm{c}}=0.1$, (c) $\mu_{\mathrm{c}}=0.94$ and $\mathrm{COV}_{-\mathrm{c}}=0.2$, all 201 cases in the database are ana- 


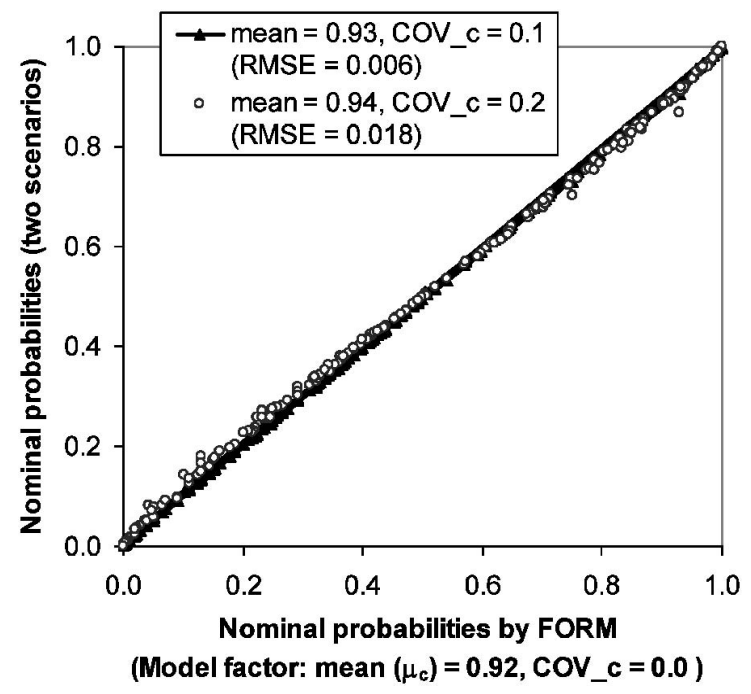

Fig. 3. Comparisons of nominal probabilities calculated with three model factors calibrated with different assumed $\operatorname{COV}$ values $(r=1)$

lyzed, and the results are compared, as shown in Fig. 3 . The RMSE between the scenario of $\mu_{\mathrm{c}}=0.92$ and COV_c $=0.0$ and the scenario of $\mu_{\mathrm{c}}=0.93$ and $\mathrm{COV}_{-\mathrm{c}}=0.1$ based on 201 cases is 0.006 , and the RMSE between the scenario of $\mu_{\mathrm{c}}=0.92$ and $\mathrm{COV}_{-\mathrm{c}}=0.0$ and the scenario of $\mu_{\mathrm{c}}=0.94$ and $\mathrm{COV}_{-\mathrm{c}}=0.2$ is 0.018 . Little difference in the calculated nominal probabilities $\left(P_{\mathrm{L} 3}\right)$ is seen among the results obtained by using different characterizations of the model factor that was calibrated separately with different assumed $\mathrm{COV}_{-\mathrm{c}}$ values.

In summary, for the adopted limit state model, the mean of the model factor is determined to be $\mu_{\mathrm{c}}=0.92 \mathrm{un}$ der the assumption of $\mathrm{COV}_{-\mathrm{c}}=0$, or alternatively with the assumption of $\mathrm{COV}_{-\mathrm{c}}=0.2$ (which is approximately an optimum value), the mean of the model factor is found to be $\mu_{\mathrm{c}}=0.94$. This characterization of the model factor is considered satisfactory in re-producing the Bayesian probabilities inferred from the observed performance data. The error of the assumption of $\mathrm{COV}_{-\mathrm{c}}=0$ appears to have been adequately "realized" in the calibration process that led to the outcome of $\mu_{\mathrm{c}}=0.92$. The effect of prior probability is examined next.

Effect of Prior Probability on the Inferred Model Factor

For convenience of subsequent discussions in reference to Eq. (13), a term called prior probability ratio, $r$, is defined: $r=P(L) / P(N L)$. The model factor determined based on the reference probability inferred from Bayesian mapping function may be affected by the assumption of the prior probabilities or the prior probability ratio. An estimate of the $r$ value is thus essential. In this paper, an attempt is made to estimate this "non-informative" prior based on expert opinions and simulation results reported by Cetin et al. (2002).

\section{Estimation of Prior Probability Ratio}

Cetin et al. (2002) performed a comprehensive study on the issue of sample bias. In their studies, they tried to esti- mate weighting factors that should be used to adjust the effect of sample bias so that an unbiased final regression model can be developed. To this end, they employed expert opinions and a sophisticated Bayesian updating technique and conducted sensitivity analyses to produce an estimate of weighting factors. To minimize the regression model variance or maximize the likelihood function to account for the effect of choice-based sample bias, Cetin et al. (2002) defined weighting factors as follows:

$$
\begin{aligned}
& W_{\mathrm{L}}=Q_{\mathrm{p}} / Q_{\mathrm{s}} \\
& W_{\mathrm{NL}}=\left(1-Q_{\mathrm{p}}\right) /\left(1-Q_{\mathrm{s}}\right)
\end{aligned}
$$

where

$$
\begin{aligned}
W_{\mathrm{L}}= & \text { weighting factor to apply to liquefied cases in } \\
& \text { the sample, } \\
W_{\mathrm{NL}}= & \text { weighting factor to apply to non-liquefied cases } \\
& \text { in the sample, } \\
Q_{\mathrm{p}}= & \text { proportion of liquefaction sites in the popula- } \\
& \text { tion, and } \\
Q_{\mathrm{s}}= & \text { proportion of liquefaction sites in a sample. }
\end{aligned}
$$

It is noted that the proportion of liquefaction sites in the population $\left(Q_{\mathrm{p}}\right)$ that contains a given sample is generally unknown. On the other hand, the proportion of liquefaction sites in the given sample $\left(Q_{\mathrm{s}}\right)$ can readily be determined. Cetin (2000) surveyed experts for opinions about weighting factors, and the results indicated the ratio of $W_{\mathrm{NL}}$ over $W_{\mathrm{L}}$ fell in the range of 1 to 3 , with the most common range from 1.5 to 2.0 . This agrees with the intuition that the effect of non-liquefied cases should be increased to compensate the fact that sampling is generally biased toward liquefied cases in field investigation. Furthermore, based on the axiom of the probability theory, both $Q_{\mathrm{p}}$ and $Q_{\mathrm{s}}$ must fall in the range of 0 to 1 . Mathematically, it can be proven from Eq. (16) that $W_{\mathrm{L}}<1$ and $W_{\mathrm{NL}}>1$. For the unknown population that contains the data set employed by Cetin et al. (2002), which includes 112 liquefied cases and 89 non-liquefied cases, the maximum likelihood analysis conducted by Cetin et al. (2002) using the information of the biased sample yielded $W_{\mathrm{L}}=$ 0.8 and $W_{\mathrm{NL}}=1.2$, and the ratio of $W_{\mathrm{NL}} / W_{\mathrm{L}}=1.5$.

The results obtained by Cetin et al. (2002) provide a basis for estimation of the prior probability ratio in the population. In this regard, it is noted that the term $Q_{\mathrm{p}}$ defined in Eq. (16) is the probability of liquefaction $P(L)$ in the population, which is essentially the prior probability required for the development of Bayesian mapping function using a sample (see Eq. (13)). Thus, the prior probability $P(L)$ can be determined with the following equation that is derived based on Eq. (16):

$$
P(L)=Q_{\mathrm{p}}=\frac{1}{1+\left(W_{\mathrm{NL}} / W_{\mathrm{L}}\right)\left[\left(1-Q_{\mathrm{s}}\right) / Q_{\mathrm{s}}\right]}
$$

Using the results of $W_{\mathrm{L}}=0.8$ and $W_{\mathrm{NL}}=1.2$ for a sample with $Q_{\mathrm{s}}=0.56$ (112 liquefied cases in a sample of 201 cases) obtained by Cetin et al. (2002), the value of $Q_{\mathrm{p}}$ is determined to be 0.46 , and thus, the prior probability ratio $r$ is determined to be 0.85 .

Recall that the expert opinions yielded a range of 1.0 to 
3.0 for the ratio $W_{\mathrm{NL}} / W_{\mathrm{L}}$, while the most probable value obtained by Cetin et al. (2002) is 1.5. Based on these results, an approximate distribution, namely, triangular distribution, of the variable $W_{\mathrm{NL}} / W_{\mathrm{L}}$ may be constructed with a minimum at 1.0 , a maximum at 3.0 , and a mode at 1.5. With the assumption of a triangular distribution of $W_{\mathrm{NL}} / W_{\mathrm{L}}$, instead of a constant (presumably, the most probable estimate), the variables $Q_{\mathrm{p}}$ and $r$ become random variables and their distributions can be derived. Numerical solutions of the first moment and the second moment of the prior probability ratio $(r)$ yield the following results: the mean $\mu_{\mathrm{r}}=0.82$ and the standard deviation $\sigma_{\mathrm{r}}$ $=0.179$.

Furthermore, the effect of possible variation in the estimated most probable value of $W_{\mathrm{NL}} / W_{\mathrm{L}}$ is examined. Using a mode of 1.3 in the assumed triangular distribution of $W_{\mathrm{NL}} / W_{\mathrm{L}}$, instead of 1.5 , yields $\mu_{\mathrm{r}}=0.85$ and $\sigma_{\mathrm{r}}=$ 0.183 ; using a mode of 1.7 yields $\mu_{\mathrm{r}}=0.78$ and $\sigma_{\mathrm{r}}=0.172$. Approximately, a $13 \%$ change in the estimated mode (most probable value) of the variable $W_{\mathrm{NL}} / W_{\mathrm{L}}$ results in less than $5 \%$ change in both $\mu_{\mathrm{r}}$ and $\sigma_{\mathrm{r}}$. Thus, the estimate of $\mu_{\mathrm{r}}=0.82$ and $\sigma_{\mathrm{r}}=0.18$ that was based on results of the comprehensive study by Cetin et al. (2002) appears to be quite reasonable. It is interesting to note that the assumption of a prior probability ratio of $r=1$ used in the initial analysis presented previously actually came within one standard deviation of the most probable estimate (mode $=0.85)$ or the mean $(0.82)$.

With the knowledge of prior probability ratio, $\mu_{\mathrm{r}}=$ 0.82 and $\sigma_{\mathrm{r}}=0.18$, the model factor for the adopted limit state model (the modified Youd et al. model) can be recalibrated. For example, with the prior probability ratio of $r=\mu_{\mathrm{r}}=0.82$, the calibration using the database of 201 cases yields the optimum mean model factor $\mu_{\mathrm{c}}=0.96 \mathrm{un}$ der the assumption of $\mathrm{COV}_{-\mathrm{c}}=0$. For an additional confirmation that the assumption of $\mathrm{COV}_{-\mathrm{c}}=0$ would not incur much error, this calibration is re-performed with the assumption of $\mathrm{COV}_{-\mathrm{c}}=0.2$, and the optimum mean model factor becomes $\mu_{\mathrm{c}}=0.98$. Figure 4 compares the nominal probabilities $\left(P_{\mathrm{L} 3}\right)$ calculated for the 201 cases

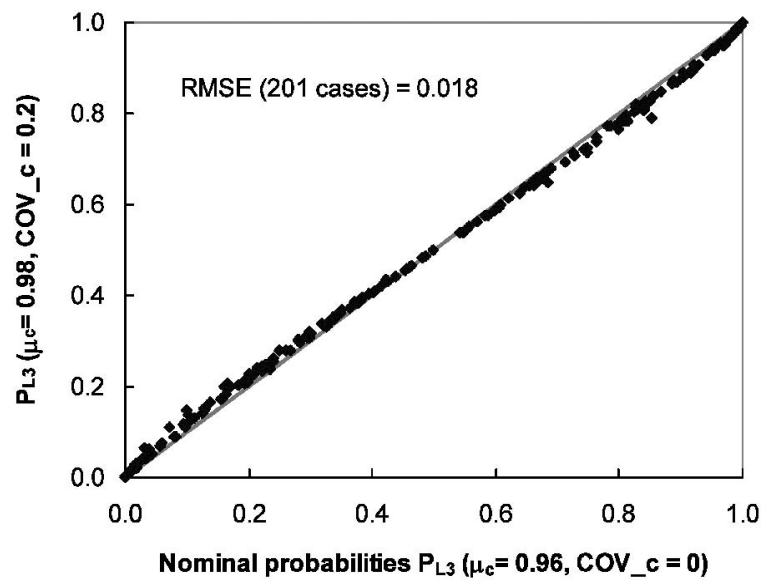

Fig. 4. Comparisons of nominal probabilities calculated with two model factors calibrated with different assumed COV values $(r=$ 0.82) using the two sets of model factor statistics, (a) $\mu_{\mathrm{c}}=0.96$ and $\mathrm{COV}_{-\mathrm{c}}=0$, and (b) $\mu_{\mathrm{c}}=0.98$ and $\mathrm{COV}_{-\mathrm{c}}=0.2$. Again, little difference between the two sets of nominal probabilities is observed from the results shown in Fig. 4, indicating the appropriateness of assuming $\mathrm{COV}_{-\mathrm{c}}=0$ for model factor calibration using the observed performance data. An estimate of the variation of $P_{\mathrm{L} 3}$, denoted as $\sigma_{P_{\mathrm{L}} 3}$, as a result of this assumption may be made based on the RMSE shown in Figs. 3 and 4. This variation is estimated to be $\sigma_{P_{\mathrm{L} 3}} \approx 0.02$.

\section{Effect of Prior Probability Ratio on Model Factor}

Because the prior probability ratio is shown to be a random variable with $\mu_{\mathrm{r}}=0.82$ and $\sigma_{\mathrm{r}}=0.18$, instead of a constant, it is essential to investigate the effect of the prior probability ratio on the back-figured model factor. To this end, a series of analyses using different assumed $r$ values (ranging from $\mu_{\mathrm{r}}-3 \sigma_{\mathrm{r}}=0.28$ to $\mu_{\mathrm{r}}+3 \sigma_{\mathrm{r}}=1.36$ ) are conducted. With each assumed $r$ value, a Bayesian mapping function is obtained and a model factor is backfigured using the approach described previously. Figure 5 shows the computed relationship between the model factor (the optimum $\mu_{\mathrm{c}}$ at an assumed $\mathrm{COV}_{-\mathrm{c}}=0$ ) and the prior probability ratio. Curve-fitting of the data shown in Fig. 5 using the least square principle yields $\left(R^{2}=0.999\right.$, standard error $=0.004)$ :

$$
\mu_{\mathrm{c}}=1.45-0.78\left(\frac{r}{r+0.48}\right)
$$

Equation (18) quantifies the effect of the prior probability ratio on the inferred model factor. The standard error of the estimate by Eq. (18) is considered negligible. At the mean $r=\mu_{\mathrm{r}}=0.82$, Eq. (18) yields $\mu_{\mathrm{c}}=0.96$, which is practically the same as the mean model factor determined previously from a direct calibration analysis. It is interesting to note that according to Eq. (18), $\mu_{\mathrm{c}}=0.95$ at the mode $r=0.85$, and thus, the difference between the model factor calibrated using the mode $(r=0.85)$ and the mean $(r=0.82)$ is quite negligible. Furthermore, Eq. (18) yields $\mu_{\mathrm{c}}=0.92$ at $r=1$, which is equal to the mean model factor obtained in the initial calibration analysis under the assumption of $r=1$. Consistent results presented above indicate the soundness and robustness of Eq. (18).

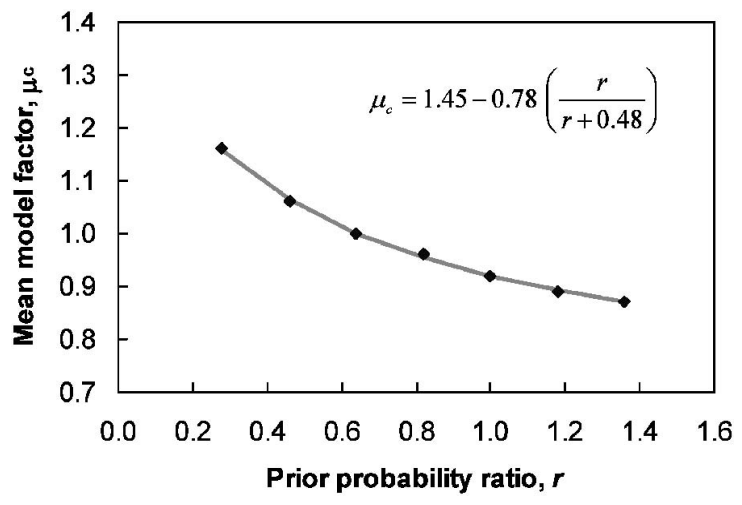

Fig. 5. Relationship between the model factor (the optimum $\mu_{\mathrm{c}}$ at the assumed COV_c $=0$ ) and the prior probability ratio 


\section{Nominal Probability Based on the Calibrated Model Factor}

With the knowledge of the limit state model, the model uncertainty $\left(\mu_{\mathrm{c}}=0.96\right.$ and $\mathrm{COV}_{-\mathrm{c}}=0$ at the mean $r=$ 0.82 ), the case-specific parameter uncertainty, and the correlations among the input variables, the FORM analysis can be performed for a given case, and the reliability index and the nominal probability of liquefaction $\left(P_{\mathrm{L} 3}\right.$, or simply, $P_{\mathrm{L}}$ hereinafter) can be determined.

It should be emphasized that the probability determined through the FORM analysis is a point estimate, meaning that $P_{\mathrm{L}}$ is a single value for a given case. However, because of the variation of the prior probability ratio $r$ and its effect on the calibrated model factor (as reflected in Eq. (18)), it would be of interest to investigate possible variation in the calculated $P_{\mathrm{L}}$ accordingly. To this end, it is noted that the mean model factor $\left(\mu_{\mathrm{c}}\right)$ determined from Eq. (18) is actually the mean of $\mu_{\mathrm{c}}$, which is denoted herein as $\bar{\mu}_{\mathrm{c}}$. The variation in the mean model factor $\left(\mu_{\mathrm{c}}\right)$ as a result of the variation in the estimated $r$ (which is itself a random variable) can be derived from Eq. (18). This variation, in terms of standard deviation of the mean model factor, $\sigma_{\mu_{\mathrm{c}}}$, is derived using the first order analysis (Ang and Tang, 1984) as follows:

$$
\sigma_{\mu_{\mathrm{c}}}^{2}=\left|\frac{\partial f}{\partial r}\right|^{2} \sigma_{\mathrm{r}}^{2}=\left[\frac{-0.37}{(r+0.48)^{2}}\right]^{2} \sigma_{\mathrm{r}}^{2}
$$

where $f$ is the function $\left(\mu_{\mathrm{c}}=f(r)\right)$ defined in Eq. (18). Substituting $r=\mu_{\mathrm{r}}=0.82$ and $\sigma_{\mathrm{r}}=0.18$ into Eq. (19), the standard deviation of the $\mu_{\mathrm{c}}$ is obtained: $\sigma_{\mu_{\mathrm{c}}}=0.04$.

Thus, for a future case, the most probable probability of liquefaction $P_{\mathrm{L}}$ can be determined through a FORM analysis that considers the model uncertainty $\left(\mu_{\mathrm{c}}=\bar{\mu}_{\mathrm{c}}=\right.$ 0.96 and $\left.\mathrm{COV}_{-c}=0\right)$, the case-specific parameter uncertainties, and the correlations among the input variables. Whereas the $P_{\mathrm{L}}$ determined by the FORM analysis for a given case is a point estimate, the variation in $P_{\mathrm{L}}$ is possible due to the variation in the estimated model factor statistics $\left(\mu_{\mathrm{c}}\right.$ and $\mathrm{COV}_{-}$) ) and/or the variation in the estimated parameter uncertainty statistics (mean $\mu_{x_{\mathrm{i}}}$ and coefficient of variation COV_ $x_{i}$ of the six input variables $\left.x_{i}, i=1,6\right)$. Since the effects of the variation in $\mathrm{COV}_{-\mathrm{c}}$ and COV_ $x_{i}$ are generally negligible, the variation of the calculated $P_{\mathrm{L}}$ due to the variation in the estimated $\mu_{\mathrm{c}}$ and $\mu_{x}$ may be expressed as follows:

$$
\sigma_{\mathrm{P}_{\mathrm{L}}}^{2}=\left|\frac{\partial P_{\mathrm{L}}}{\partial \mu_{\mathrm{C}}}\right|^{2} \sigma_{\mu_{\mathrm{c}}}^{2}+\left|\frac{\partial P_{\mathrm{L}}}{\partial \mu_{x_{i}}}\right|_{i=1,6}^{2} \sigma_{\mu_{x_{i}}}^{2}
$$

where

$\sigma_{\mathrm{P}_{\mathrm{L}}}=$ standard deviation of the calculated $P_{\mathrm{L}}$,

$\sigma_{\mu_{x i}}=$ standard deviation of the mean of variable $x_{i}$, and $\mu_{x_{i}}=$ mean of variable $x_{i}$.

It is further noted that in geotechnical engineering practice, the mean and standard deviation of an input variable are almost always treated as point estimates, and thus, $\sigma_{\mu_{x i}}=0$ can be assumed. This follows that Eq. (20) can be reduced into:

$$
\sigma_{\mathrm{P}_{\mathrm{L}}-\mathrm{c}}^{2}=\left|\frac{\partial P_{\mathrm{L}}}{\partial \mu_{\mathrm{C}}}\right|^{2} \sigma_{\mu_{\mathrm{c}}}^{2}
$$

where $\sigma_{\mathrm{P}_{\mathrm{L}}-\mathrm{c}}$ is the standard deviation of the $P_{\mathrm{L}}$ caused only by the variation of $\mu_{\mathrm{c}}$. Equation (21) can further be approximated as:

$$
\sigma_{\mathrm{P}_{\mathrm{L}-\mathrm{c}}}=\left|\frac{\partial P_{\mathrm{L}}}{\partial \mu_{\mathrm{C}}}\right| \sigma_{\mu_{\mathrm{c}}} \approx\left(\frac{\Delta P_{\mathrm{L}}}{\Delta \mu_{\mathrm{c}}}\right) \sigma_{\mu_{\mathrm{c}}}
$$

By taking $\Delta \mu_{\mathrm{c}}=2 \sigma_{\mu_{\mathrm{c}}}$, Eq. (22) is reduced to (after Duncan, 2000):

$$
\sigma_{\mathrm{P}_{\mathrm{L}-\mathrm{c}}} \approx\left(\frac{\Delta P_{\mathrm{L}}}{2}\right)=\frac{\left|P_{\mathrm{L}}^{+}-P_{\mathrm{L}}^{-}\right|}{2}
$$

where

$$
\begin{aligned}
P_{\mathrm{L}}^{+}= & \text {probability of liquefaction obtained through a } \\
& \text { FORM analysis that uses a model factor of } \mu_{\mathrm{c}}= \\
& \bar{\mu}_{\mathrm{c}}+1 \sigma_{\mu_{\mathrm{c}}}=1.0 \text { with } \mathrm{COV}_{-\mathrm{c}}=0 \text {, and } \\
P_{\mathrm{L}}^{-}= & \text {probability of liquefaction obtained through a } \\
& \text { FORM analysis that uses a model factor of } \mu_{\mathrm{c}}= \\
& \bar{\mu}_{\mathrm{c}}-1 \sigma_{\mu_{\mathrm{c}}}=0.92 \text { with } \mathrm{COV}_{-\mathrm{c}}=0 .
\end{aligned}
$$

By definition of the derivative, the approximation in Eq. (22) or Eq. (23) is acceptable as long as $\Delta \mu_{\mathrm{c}}$ is small enough. Results of the analysis of limited cases in the database (see EXAMPLE APPLICATION presented in the next section) confirm that $\Delta \mu_{\mathrm{c}}$ is indeed small enough and thus Eq. (23) is valid. It should be noted that approximate formulation such as Eq. (23) has previously been reported by Hassan and Wolff (1999), Duncan (2000), and Gutierrez et al. (2003) for other geotechnical applications.

Finally, recall that the variation in the calculated $P_{\mathrm{L}}$ as a result of the assumption of $\mathrm{COV}_{-\mathrm{c}}=0$ is approximately equal to 0.02 (due to adequate Bayesian calibration of model factor at the assumed $\mathrm{COV}_{-}$). Assuming that the two sources of variation, caused by the assumption of $\mathrm{COV}_{-\mathrm{c}}=0$ and by the variation in the estimated mean model factor $\left(\mu_{\mathrm{c}}\right)$, are independent from each other, the variation in the calculated $P_{\mathrm{L}}$ can be further combined into:

$$
\sigma_{\mathrm{P}_{\mathrm{L}}}=\sqrt{0.02^{2}+\sigma_{\mathrm{P}_{\mathrm{L}}-\mathrm{c}}^{2}}
$$

In summary, Eq. (23) is an approximate solution that can be used to estimate the variation in the mean $P_{\mathrm{L}}$ caused by the variation in the model factor of the adopted limit state model (the modified Youd et al. model). To evaluate Eq. (23) for $\sigma_{\mathrm{P}_{\mathrm{L}} \mathrm{c}}$, only two FORM analyses (using $\mu_{\mathrm{c}}=0.92$ and 1.0 separately) are needed. Finally, the total variation in the calculated $P_{\mathrm{L}}$ can be expressed as a standard deviation defined in Eq. (24) by further considering possible variation due to the assumption of $\mathrm{COV}_{-}=0$.

\section{ESTIMATION OF PARAMETER UNCERTAIMTY FOR RELIABILITY ANALYSIS USING FORM}

The results presented in the previous sections have established a comprehensive and yet practical framework 
for conducting reliability analysis to determine the probability of liquefaction. The section that follows immediately will present an example application using a practical tool (i.e., a spreadsheet that implements the entire reliability analysis framework). In the current section, the objective is to provide some guidance for practicing engineers on the estimation of parameter uncertainty that is required for FORM analysis of a specific case.

In general, the evaluation of parameter uncertainty for a specific case is the duty of the engineer in charge. For each input variable that is required in the limit state equation (Eq. (12)), this process involves the estimation of the mean and standard deviation if the variable is assumed to follow normal or lognormal distribution. The engineer usually can make a pretty good estimate of the mean of a variable even with limited data. This probably has to do with the well-established statistics theory that the "sample mean" is a best estimate of the "population mean." Thus, the following discussion focuses on the estimation of standard deviation of each input random variable.

Duncan (2000) suggested that the standard deviation of a random variable may be obtained by one of the following three methods: 1) direct calculation from data, 2) estimate based on published coefficient of variation (COV), and 3) estimate based on the "three-sigma rule." The first two methods are straightforward. In the last method, the knowledge of the highest conceivable value (HCV) and the lowest conceivable value $(\mathrm{LCV})$ of the variable is used to calculate the standard deviation $\sigma$ as follows (Duncan, 2000):

$$
\sigma=\frac{\mathrm{HCV}-\mathrm{LCV}}{6}
$$

It should be noted that the engineer tends to under-estimate the range of a given variable (and thus, the standard deviation), particularly if the estimate was based on very limited data and judgment was required. Thus, for a small sample size, a value of less than 6 should be used for the denominator in Eq. (25). Whenever in doubt, a sensitivity analysis should be conducted to investigate the effect of different levels of uncertainty (in terms of COV) of a particular variable on the results of reliability analysis.

Typical ranges of COVs of the input variables according to the published data are listed in Table 2. It should be noted that the COVs of the earthquake parameters, $a_{\text {max }}$ and $M_{\mathrm{w}}$, listed in Table 2 are based on values reported in the published databases of case histories where recorded strong ground motions and/or locally calibrated data were available. The COV of $a_{\max }$ based on general attenuation relationships could easily be as high as 0.50 (Haldar and Tang, 1979). According to Youd et al. (2001), for a future site in the U.S., the variable $a_{\max }$ may be estimated using one of the following methods:

1) Using empirical correlations of $a_{\max }$ with the earthquake magnitude, the distance from the seismic energy source, and local site conditions.

2) Performing local site response analysis (e.g., using
Table 2. Typical coefficients of variation of input variables (Juang et al., 2008b)

\begin{tabular}{ccl}
\hline $\begin{array}{c}\text { Random } \\
\text { Variable }\end{array}$ & $\begin{array}{c}\text { Typical range } \\
\text { of COV }\end{array}$ & \multicolumn{1}{c}{ References } \\
\hline$N_{1,60}$ & $0.10-0.40$ & $\begin{array}{l}\text { Harr (1987); } \\
\text { Gutierrez et al. (2003); } \\
\text { Phoon and Kulhawy (1999) }\end{array}$ \\
FC & $0.05-0.35$ & Gutierrez et al. (2003) \\
$\sigma_{\mathrm{v}}^{\prime}$ & $0.05-0.20$ & Juang et al. (1999) \\
$\sigma_{\mathrm{v}}$ & $0.05-0.20$ & Juang et al. (1999) \\
$a_{\max }$ & $0.10-0.20^{\mathrm{b})}$ & Juang et al. (1999, 2008b) \\
$M_{\mathrm{w}}$ & $0.05-0.10$ & Juang et al. $(1999,2008 \mathrm{~b})$ \\
\hline
\end{tabular}

a) The word "typical" here implies the range approximately bounded by the 15 th percentile and the 85 th percentile, estimated from case histories in the existing databases such as Cetin (2000). Published COVs are also considered in the estimate given here. The actual COV values could be higher or lower, depending on the variability of the site and the quality and quantity of data that are available.

b) The range is based on values reported in the published databases of case histories where recorded strong ground motions and locally calibrated data were available. However, the COV of $a_{\max }$ based on general attenuation relationships or amplification factors could easily be as high as or over 0.50. The reader is referred to Juang et al. (2008b) for further discussion of this issue.

SHAKE or similar software) to account for local site effects.

3) Using the USGS National Seismic Hazard web pages and the NEHRP amplification factors.

Further discussion on the first two methods is beyond the scope of this paper, as this is best handled by the engineer in charge for a specific case. The third method, the amplification factor approach, is briefly discussed in the following. The USGS National Hazard Maps (Frankel et al., 2002) provide rock outcrop peak ground acceleration (PGA) for a specified locality based on latitude/longitude. The USGS National Hazard Maps web site (USGS, 2002a) provides PGA value at each of the six seismic hazard levels, which corresponds to earthquake return periods of 4975, 2475, 975, 475, 224, and 108 years, respectively. Thus, for a given locality, a PGA can be obtained for a specified probability of exceedance in an exposure time from this USGS web site.

For liquefaction analysis, the rock PGA needs to be converted to peak ground surface acceleration at the site, $a_{\text {max }}$. Ideally, the conversion should be carried out based on site response analysis. Various simplified procedures are also available for an estimate of $a_{\max }$ (e.g., Gutierrez et al., 2003; Stewart et al., 2003). As an example, a simplified procedure for estimating $a_{\max }$, perhaps in the simplest form, is expressed as follows:

$$
a_{\max }=F_{\mathrm{a}}(\mathrm{PGA})
$$

where $F_{\mathrm{a}}$ is the amplification factor, which, in a simplest form, may be expressed as a function of rock PGA and the NEHRP site class. Figure 6 shows an example of a simplified chart for the amplification factor. The NEHRP site classes used in Fig. 6 are based on the mean shear wave velocity of soils in the top $30 \mathrm{~m}$, as listed in Table 3 . Other simplified solutions for the amplification factor include regression equations developed by Stewart et al. 


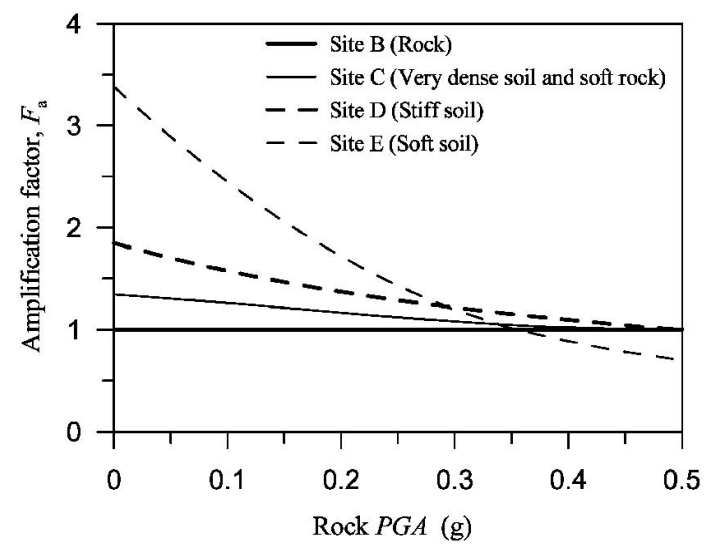

Fig. 6. Amplification factor as a function of rock PGA and the NEHRP site class (after Gutierrez et al., 2003; Juang et al., 2008b)

Table 3. Site classes (categories) in NEHRP provisions (NEHRP, 1998)

\begin{tabular}{cl}
\hline $\begin{array}{c}\text { NEHRP } \\
\text { Category }\end{array}$ & \multicolumn{1}{c}{$\begin{array}{c}\text { Description of soil conditions with } \\
\text { respect to shear wave velocity }\end{array}$} \\
\hline A & $\begin{array}{l}\text { Hard rock with measured mean shear wave velocity in the } \\
\text { top } 30 \mathrm{~m}, \bar{v}_{\mathrm{s}}>1,500 \mathrm{~m} / \mathrm{s}\end{array}$ \\
B & Rock with $760 \mathrm{~m} / \mathrm{s}<\bar{v}_{\mathrm{s}} \leq 1,500 \mathrm{~m} / \mathrm{s}$ \\
C & Dense soil and soft rock with $360 \mathrm{~m} / \mathrm{s}<\bar{v}_{\mathrm{s}} \leq 760 \mathrm{~m} / \mathrm{s}$ \\
D & Stiff soil with $180 \mathrm{~m} / \mathrm{s}<\bar{v}_{\mathrm{s}} \leq 360 \mathrm{~m} / \mathrm{s}$ \\
E & $\begin{array}{l}\text { Soil with } \bar{v}_{\mathrm{s}} \leq 180 \mathrm{~m} / \mathrm{s} \text { or any profile with more than } 3 \mathrm{~m} \text { of } \\
\text { soft clay (plasticity index PI }>20, \text { water content } w>40 \%\end{array}$ \\
& $\begin{array}{l}\left.\text { and undrained shear strength } s_{\mathrm{u}}<25 \mathrm{kPa}\right) \\
\text { Soils requiring a site-specific study, e.g., liquefiable soils, } \\
\text { highly sensitive clays, collapsible soils, organic soils, etc. }\end{array}$ \\
\hline
\end{tabular}

(2003).

The rock outcrop PGA is generally assumed to follow lognormal distribution (Kramer and Mayfield, 2007). The amplification factor $F_{\mathrm{a}}$ also follows lognormal distribution (Stewart et al., 2003). Therefore, the variable $a_{\max }$ can also be characterized with lognormal distribution, and thusly in a simplified solution, the mean and standard deviation of $a_{\max }$ can easily be determined based on the mean and standard deviation of PGA and $F_{\mathrm{a}}$. For practical applications, this simplified solution is appropriate.

For reliability analysis of a future site in a specified locality in the U.S., the magnitude of $M_{\mathrm{w}}$ can also be derived from the USGS web pages through a de-aggregation (USGS, 2002b). The task of seismic hazard de-aggregation involves the determination of earthquake parameters, principally magnitude and distance, for use in a seismic-resistant design. The seismic hazard curve presented in the USGS web page is de-aggregated to examine the "contribution to hazard" (in terms of frequency) as a function of magnitude and distance. These plots of "contribution to hazard" as a function of magnitude and distance are useful for specifying design earthquakes. On the available de-aggregation plots from the USGS web site, the height of each bar represents the percent contribution of that magnitude and distance pair (or bin) to the specified probabilities of exceedance. The distribution of the heights of these bars (i.e., frequencies) is essentially a joint probability mass function of magnitude and distance. When this joint mass function is "integrated" along the axis of distance, the probability mass or distribution function of the magnitude is obtained.

In summary, the PGA and $M_{\mathrm{w}}$ may be obtained for a given site at a specified hazard level. The selected PGA is converted to $a_{\max }$, and the pair of $a_{\max }$ and $M_{\mathrm{w}}$ is then used in the liquefaction evaluation. For reliability analysis, the mean value and the standard deviation (and thus, the coefficients of variation) of $a_{\max }$ and $M_{\mathrm{w}}$ can be determined from their respective distributions. If such distributions are not available, the coefficients of variation for these two seismic parameters may be estimated using Table 2 as a guide. It should be noted that the ranges of COV listed in Table 2 are estimated based on published databases of case histories where recorded strong ground motions and locally calibrated data are available. However, the COV of $a_{\max }$ based on general attenuation relationships or amplification factors for a given site considering all possible ground motions at all hazard levels could easily be as high as or over 0.50 . For situations like that, it is vital to construct the joint distribution of $a_{\max }$ and $M_{\mathrm{w}}$, considering all possible ground motions at all hazard levels. Such approach is, however, beyond the scope of this paper; the interested reader is referred to Juang et al. (2008a) for this issue.

\section{EXAMPLE APPLICATION}

This example concerns a non-liquefied case in the database. Field observation of the site, designated as Araha$m a$ (Cetin et al., 2004), indicated no evidence of liquefaction during the 1978 Miyagiken-Oki earthquake $\left(M_{\mathrm{w}}=\right.$ $\left.6.7, a_{\max }=0.1 \mathrm{~g}\right)$. The mean values of seismic and soil parameters at the critical depth $(5.0 \mathrm{~m})$ are given as follows: $N_{1,60}=14.1, \quad \mathrm{FC}=0 \%, \sigma_{\mathrm{v}}^{\prime}=44.9 \mathrm{kPa}, \sigma_{\mathrm{v}}=85.0$ $\mathrm{kPa}, a_{\max }=0.1 \mathrm{~g}$, and $M_{\mathrm{w}}=6.7$. The corresponding coefficients of variation of these parameters are assumed to be $0.191,0.0,0.185,0.206,0.2$, and 0.1 , respectively. Reliability analysis using FORM with the knowledge of the model factor $\left(\mu_{\mathrm{c}}=\bar{\mu}_{\mathrm{c}}=0.96\right.$ and $\left.\mathrm{COV}_{-\mathrm{c}}=0\right)$ yields a reliability index of $\beta_{3}=1.592$ and the nominal probability of liquefaction of $P_{\mathrm{L}}=P_{\mathrm{L} 3}=0.056$. As noted previously, the result of the FORM analysis is a point estimate. This solution may be obtained easily with a computer code (Yang, 2003) or a simple spreadsheet (Low and Tang, 1997; Phoon, 2004; Juang et al., 2006), as shown in Fig. 7. The spreadsheet developed specifically for this FORM analysis of liquefaction potential is available from the first author upon request.

To estimate the variation of $P_{\mathrm{L}}$, two additional FORM analyses with different $\mu_{\mathrm{c}}$ values $\left(\mu_{\mathrm{c}}=\bar{\mu}_{\mathrm{c}}-1 \sigma_{\mu_{\mathrm{c}}}=0.92\right.$ and $\mu_{\mathrm{c}}=\bar{\mu}_{\mathrm{c}}+1 \sigma_{\mu_{\mathrm{c}}}=1.0$ separately) are performed, which yields for this case, $P_{\mathrm{L}}^{+}=0.047$ and $P_{\mathrm{L}}^{-}=0.067$. Thus, according to Eq. (23), the variation of the mean $P_{\mathrm{L}}$ caused by the variation in the estimated $\mu_{\mathrm{c}}$ is determined to be $\sigma_{\mathrm{P}_{\mathrm{L}}-\mathrm{c}}$ $=0.0099$. Although the variation of $P_{\mathrm{L}}$ appears quite 


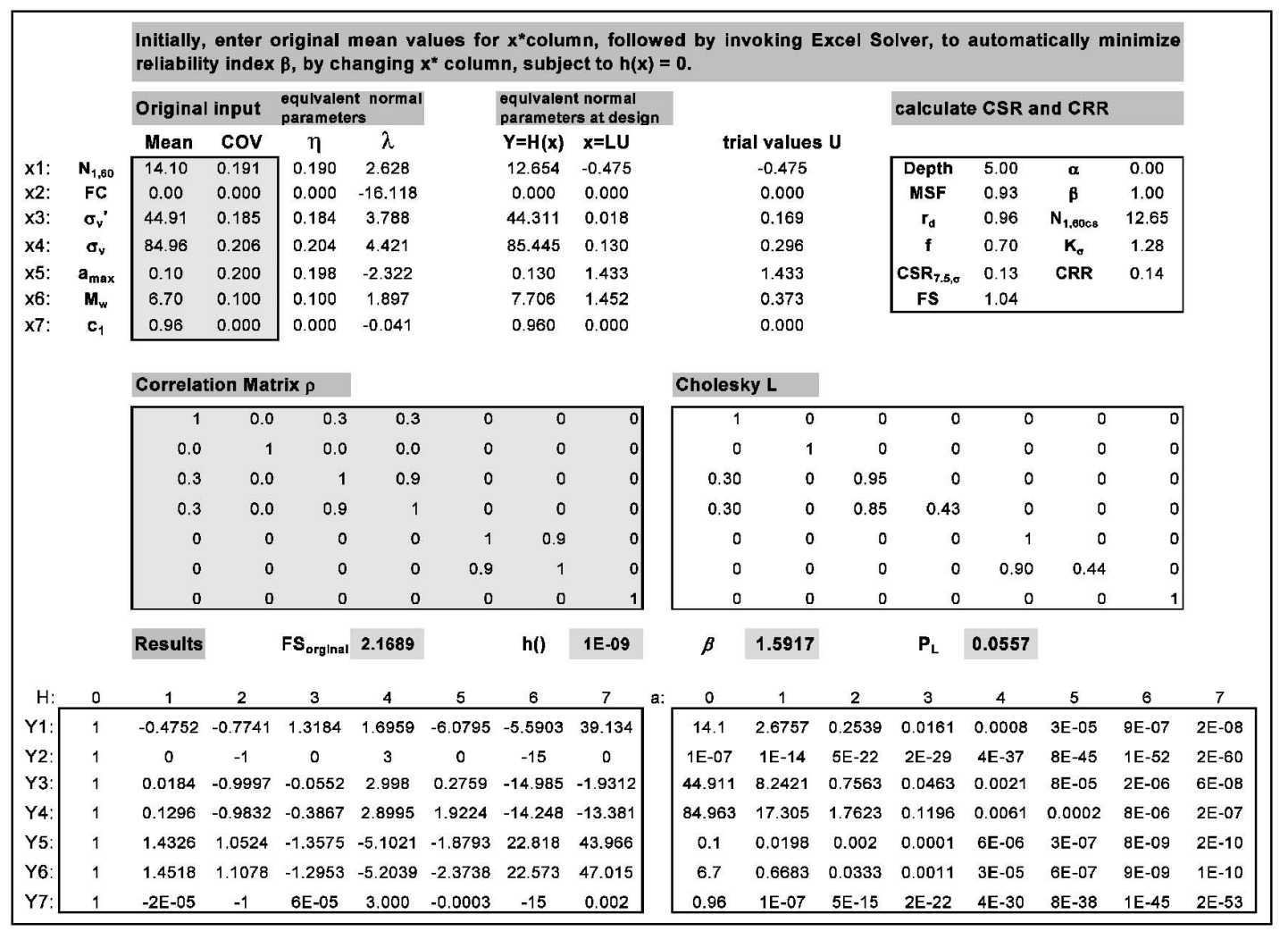

Fig. 7. Spreadsheet that implements the entire FORM analysis (after Juang et al., 2008b)

Table 4. Summary of the sensitivity analysis of Eq. (23)

\begin{tabular}{|c|c|c|c|c|}
\hline \multirow[b]{2}{*}{ Step Size } & \multirow[b]{2}{*}{ Variant of Eq. (23) (for different step sizes) } & \multicolumn{3}{|c|}{$\sigma_{\mathrm{P}_{\mathrm{L}}-\mathrm{c}}$} \\
\hline & & $\begin{array}{c}\text { Arahama Site } \\
1978 \text { Miyagiken-Oki } \\
\text { earthquake }\end{array}$ & $\begin{array}{c}\text { Kobe No. } 35 \text { site } \\
1995 \text { Hyogoken-Nambu } \\
\text { earthquake }\end{array}$ & $\begin{array}{c}\text { San Juan B-5 Site } \\
1977 \text { Argentina } \\
\text { earthquake }\end{array}$ \\
\hline$\Delta \mu_{\mathrm{c}}=2 \sigma_{\mu_{\mathrm{c}}}$ & $\sigma_{\mathrm{P}_{\mathrm{L}}-\mathrm{c}}=\left|P_{\mathrm{L}}^{+}-P_{\mathrm{L}}^{-}\right| / 2$ & 0.0099 & 0.0246 & 0.0314 \\
\hline$\Delta \mu_{\mathrm{c}}=6 \sigma_{\mu_{\mathrm{c}}}$ & $\sigma_{\mathrm{P}_{\mathrm{L}}-\mathrm{c}}=\left|P_{\mathrm{L}}^{+++}-P_{\mathrm{L}}^{---}\right| / 6$ & 0.0103 & 0.0249 & 0.0322 \\
\hline
\end{tabular}

small in this non-liquefied case, it actually represents approximately $18 \%$ of variation from the mean of $P_{\mathrm{L}}=$ 0.056 .

To examine the effect of the "step size", $\Delta \mu_{\mathrm{c}}$, on the approximation in Eqs. (22) and (23), the same problem is analyzed with two different step sizes, (a) $\Delta \mu_{\mathrm{c}}=4 \sigma_{\mu_{\mathrm{c}}}$ and (b) $\Delta \mu_{\mathrm{c}}=6 \sigma_{\mu_{\mathrm{c}}}$. In the first case, $\sigma_{\mathrm{P}_{\mathrm{L}}-\mathrm{c}}=\left|P_{\mathrm{L}}^{++}-P_{\mathrm{L}}^{--}\right| / 4$ where $P_{\mathrm{L}}^{++}$is the probability of liquefaction obtained through a FORM analysis that use $\mu_{\mathrm{c}}=\bar{\mu}_{\mathrm{c}}+2 \sigma_{\mu_{\mathrm{c}}}=1.04$, and $P_{\mathrm{L}}^{--}$is the probability of liquefaction obtained with $\mu_{\mathrm{c}}=\bar{\mu}_{\mathrm{c}}-2 \sigma_{\mu_{\mathrm{c}}}=0.88$. In the second case, $\sigma_{\mathrm{P}_{\mathrm{L}}-\mathrm{c}}=\mid P_{\mathrm{L}}^{++}-$ $P_{\mathrm{L}}^{---} \mid / 6$ where $P_{\mathrm{L}}^{++}$is the probability of liquefaction obtained through a FORM analysis that use $\mu_{\mathrm{c}}=\bar{\mu}_{\mathrm{c}}+3 \sigma_{\mu_{\mathrm{c}}}$ $=1.08$, and $P_{\mathrm{L}}^{---}$is the probability of liquefaction obtained with $\mu_{\mathrm{c}}=\bar{\mu}_{\mathrm{c}}-3 \sigma_{\mu_{\mathrm{c}}}=0.84$. For the same case as described previously, the two alternatives that used greater step sizes yield practically the same $\sigma_{\mathrm{P}_{\mathrm{L}}-\mathrm{c}} \approx 0.01$, as shown in Table 4. It is noted that the results of the sensitivity analysis for two other cases (presented later) are also included in Table 4. These results verify the validity of Eq. (23) that was previously examined and reported by other investigators (Hassan and Wolff, 1999; Duncan, 2000; Gutierrez et al., 2003).

Finally, the variation in the calculated $P_{\mathrm{L}}$, in terms of standard deviation, can be calculated with Eq. (24), which yields $\sigma_{\mathrm{P}_{\mathrm{L}}}=0.022$. By taking an approximation of the mean plus and minus 3 times standard deviation, the probability of liquefaction for this case (assuming that it is predicted before the event) would fall approximately in the range of 0.0 to 0.123 . This result suggests that liquefaction is extremely unlikely to occur at this site when subjected to the 1978 Miyagiken-Oki earthquake $\left(M_{\mathrm{w}}=\right.$ $6.7, a_{\max }=0.1 \mathrm{~g}$ ), which agrees with field observation of no liquefaction. 


\section{COMPARISON WITH EXISTING METHODS}

The probabilities of liquefaction of the case analyzed previously along with additional examples are calculated with two existing empirical models. One is the empirical model established by Youd and Noble (1997) based on logistic regression analysis. The other is the empirical model established by Cetin et al. (2004) based on a more sophisticated regression analysis with Bayesian updating.

In the model by Youd and Noble (1997), the probability of liquefaction is calculated with the following equation:

$$
\begin{aligned}
\ln \left[P_{\mathrm{L}} /\left(1-P_{\mathrm{L}}\right)\right]= & -7.633+2.256 M_{\mathrm{w}}-0.258\left(N_{1,60 \mathrm{cs}}\right) \\
& +3.095(\ln \mathrm{CSR})
\end{aligned}
$$

where CSR is not "adjusted" by MSF and $K_{\sigma}$. In other words, CSR in Eq. (27) is calculated as (Seed and Idriss, 1971; Seed et al., 1985):

$$
\mathrm{CSR}=0.65\left(\frac{\sigma_{\mathrm{v}}}{\sigma_{\mathrm{v}}^{\prime}}\right)\left(\frac{a_{\max }}{g}\right)\left(r_{\mathrm{d}}\right)
$$

In the more sophisticated Bayesian regression model by Cetin et al. (2004), the probability of liquefaction is calculated with the following equation:

$$
P_{\mathrm{L}}=\Phi\left(-\frac{\left[N_{1,60}(1+0.004 \mathrm{FC})-13.32 \ln (\mathrm{CSR})-29.53 \ln \left(M_{\mathrm{w}}\right)-3.70 \ln \left(\frac{\sigma_{\mathrm{v}}^{\prime}}{P_{\mathrm{a}}}\right)+0.05 \mathrm{FC}+16.85\right]}{2.70}\right)
$$

where CSR is defined in Eq. (28), $P_{\mathrm{a}}$ is the atmospheric pressure $(\approx 100 \mathrm{kPa})$ and $\Phi$ is the cumulative standard normal distribution function.

It should be noted that a direct comparison of the FORM solution with the results obtained from the two empirical models (Eqs. (27) and (29)) is not entirely meaningful because that in the two regression-based models, only the representative values (or the mean values) of the input variables are entered into the respective equations (Eqs. (27) and (29)), whereas with the FORM solution, the variation of the input variables, the correlations among the input variables, and the model uncertainty are all directly incorporated in the reliability analysis. Nevertheless, this comparison is still desirable as it may provide some indication on the performance of the FORM solution presented.

For the same Arahama case in the 1978 Miyagiken-Oki earthquake $\left(M_{\mathrm{w}}=6.7, a_{\max }=0.1 \mathrm{~g}\right)$ presented previously, the probability of liquefaction is $P_{\mathrm{L}}=0.050$ calculated from Eq. (27) (Youd and Noble, 1997), and $P_{\mathrm{L}}=0.005$ calculated from Eq. (29) (Cetin et al., 2004). Recall that the FORM solution yielded a mean $P_{\mathrm{L}}$ of 0.056 , and a possible range of 0.0 to 0.123 . Thus, for this case, the results obtained using the three methods are consistent with each other, all suggesting that liquefaction is extremely unlikely to occur at this site when subjected to the

\begin{tabular}{|c|c|c|c|c|c|c|c|c|c|c|c|c|}
\hline \multirow{3}{*}{ Example Case } & \multicolumn{9}{|c|}{ Basic soil data of the critical layer } & & & \\
\hline & \multirow{2}{*}{$\begin{array}{l}\text { Depth } \\
\text { (m) }\end{array}$} & \multicolumn{4}{|c|}{ Mean value } & \multicolumn{4}{|c|}{$\begin{array}{l}\text { COV (required only in the } \\
\text { FORM analysis) }\end{array}$} & \multicolumn{3}{|c|}{ Probability of liquefaction } \\
\hline & & $N_{1,60}$ & $\begin{array}{l}\mathrm{FC} \\
(\%)\end{array}$ & $\begin{array}{c}\sigma_{\mathrm{v}}^{\prime} \\
(\mathrm{kPa})\end{array}$ & $\begin{array}{c}\sigma_{\mathrm{v}} \\
(\mathrm{kPa})\end{array}$ & $N_{1,60}$ & $\mathrm{FC}$ & $\sigma_{\mathrm{v}}^{\prime}$ & $\sigma_{\mathrm{v}}$ & $\begin{array}{l}\text { Youd and } \\
\text { Noble (1997) }\end{array}$ & $\begin{array}{l}\text { Cetin et al. } \\
\qquad(2004)\end{array}$ & $\begin{array}{c}\text { This study } \\
\text { mean, } \mu(\mu \pm 3 \sigma)\end{array}$ \\
\hline $\begin{array}{l}\text { Site: Arahama } \\
1978 \text { Miyagiken-Oki } \\
M_{\mathrm{w}}=6.7, a_{\max }=0.1 \mathrm{~g} \\
\text { COV of } a_{\max }=0.20 \\
\text { (Tohno and Yasuda, 1981; } \\
\text { Cetin et al., 2004) }\end{array}$ & 5.0 & 14.1 & 0 & 44.9 & 85.0 & 0.191 & 0 & 0.185 & 0.206 & 0.050 & 0.005 & $\begin{array}{l}0.056 \\
\text { (0. to } 0.123)\end{array}$ \\
\hline $\begin{array}{l}\text { Site: Kobe No. } 35 \\
1995 \text { Hyogoken-Nambu } \\
M_{\mathrm{w}}=6.9, a_{\max }=0.5 \mathrm{~g} \\
\text { COV of } a_{\max }=0.15 \\
\text { (Cetin et al., 2004) }\end{array}$ & 4.5 & 19.0 & 8 & 48.6 & 72.6 & 0.137 & 0.25 & 0.098 & 0.117 & 0.547 & 0.985 & $\begin{array}{c}0.829 \\
(0.73 \text { to } 0.92)\end{array}$ \\
\hline
\end{tabular}
1978 Miyagiken-Oki earthquake. This prediction agrees well with the field observation of no liquefaction.

Table 5. Basic data from three case histories and the probabilities of liquefaction determined with three different methods 
(a)

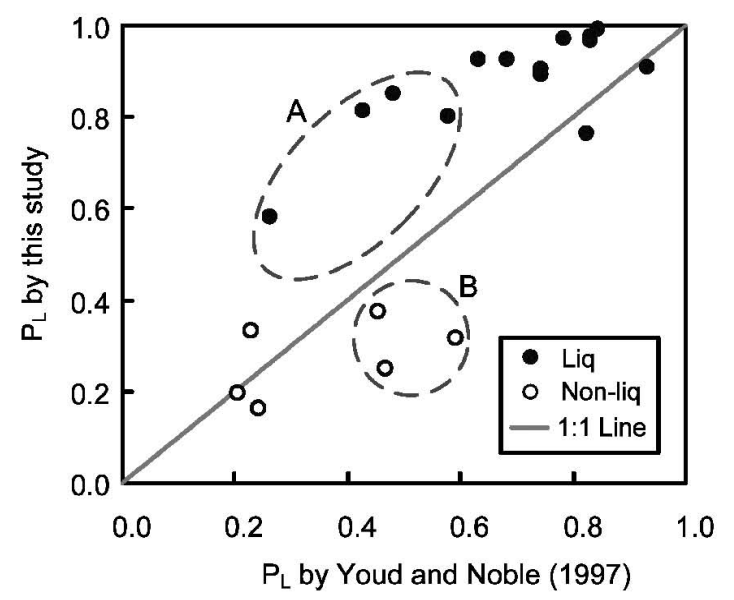

(b)

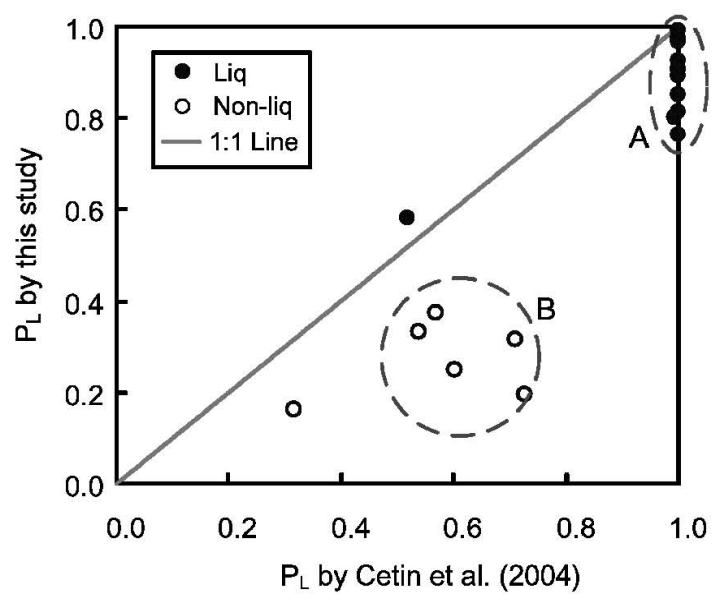

Fig. 8. Comparison of three probability-based methods with 20 case histories

To further compare the three methods, another two examples are worked out, including one liquefied case and one non-liquefied case. The liquefied case analyzed is the Kobe No. 35 site in the 1995 Hyogoken-Nambu earthquake $\left(M_{\mathrm{w}}=6.9, a_{\max }=0.5 \mathrm{~g}\right)$, and the non-liquefied case is the San Juan B-5 site in the 1977 Argentina earthquake $\left(M_{\mathrm{w}}=7.4, a_{\max }=0.2 \mathrm{~g}\right)$. The analysis presented previously is repeated for the two cases, and the results are shown in Table 5. For the liquefied case (Kobe No. 35), $P_{\mathrm{L}}=0.547$ calculated from Eq. (27) (Youd and Noble, 1997), and $P_{\mathrm{L}}$ $=0.985$ calculated from Eq. (29) (Cetin et al., 2004). The FORM solution in this paper yields a mean of 0.829 and a range of 0.73 to 0.92 . The solutions obtained using FORM (this study) and the Cetin et al. (2004) method suggest that the site is very likely to experience liquefaction when subjected to the ground shaking the level of the 1995 Hyogoken-Nambu earthquake, which agrees with the field observation. The Youd and Noble (1997) method is less accurate than the other two methods for this liquefied case.

For the non-liquefied case (San Juan B-5), the Cetin et al. (2004) method yields $P_{\mathrm{L}}=0.328$, whereas the Youd and Noble (1997) method yields $P_{\mathrm{L}}=0.377$. The FORM solution in this study yields a mean of 0.165 and a range of 0.05 to 0.28 for the San Juan B- 5 case, which compares favorably to the solutions by Cetin et al. (2004) and Youd and Noble (1997) for this non-liquefied case.

Finally, Fig. 8 shows additional comparison of the three probability-based methods using 20 case histories. These cases include 6 non-liquefied cases and 14 liquefied cases, taken from published records from the 1976 Guatemala earthquake, the 1977 Argentina earthquake, the 1978 Miyagiken-Oki earthquake, the 1971 San Fernando earthquake, the 1979 Imperial Valley earthquake, the 1994 Northridge earthquake, and the 1995 Hyogoken-Nambu earthquake (Cetin et al., 2004). Similar results as presented previously can be observed. As shown in Fig. 8(a), the probabilities of liquefaction computed with the Youd and Noble method and the proposed method (FORM analysis) in this study are quite consistent. However, for liquefied cases included in zone A, the $P_{\mathrm{L}}$ values obtained in this study are higher than those obtained with the Youd and Noble method, which indicates that the proposed method (FORM) is more accurate. For non-liquefied cases included in zone $\mathrm{B}$, the $P_{\mathrm{L}}$ values obtained in this study are lower than those obtained with the Youd and Noble method, which again indicates that the proposed method is more accurate.

As shown in Fig. 8(b), in all but one liquefied cases (zone A), the $P_{\mathrm{L}}$ values computed by the Cetin et al. (2004) method are all practically equal to 1.0 , indicating that predictions made with this method for these liquefied cases are accurate. For the same liquefied cases, the $P_{\mathrm{L}}$ values computed by the proposed method are also very high (zone A), indicating that the proposed method is also accurate in this regard. On the other hand, for the non-liquefied cases (included in zone B), the $P_{\mathrm{L}}$ values computed by the Cetin et al. (2004) method are significantly higher than those obtained with the proposed method, which is less desirable. Overall, the proposed method yields the most desirable results among the three methods examined.

Based on the results presented, it appears that the Cetin et al. (2004) method has a tendency to produce a higher estimate of the probability of liquefaction. This tendency is biased toward the conservative side-it is more likely to correctly predict liquefied cases. On the other hand, the Cetin et al. (2004) method is likely to over-estimate the probability of liquefaction of non-liquefied cases, which may not be desirable as the sites that are suitable for development would be wrongly judged to be unsuitable, and unnecessary ground improvement project could have been suggested based on incorrect prediction of the probability of liquefaction. The solutions by the Youd and Noble (1997) method are quite consistent with the FORM solutions presented in this paper. Overall, the FORM solutions appear to be able to produce reasonable estimates of the probability of liquefaction, either in liquefied cases or non-liquefied cases.

It should be noted that the comparison of the three methods made herein is only approximate and based on limited cases. In particular, the parameter uncertainties were not included in the Youd and Noble (1997) method 
and the Cetin et al. (2004) method, as they were not required in Eqs. (27) and (29), respectively. On the other hand, the FORM solution considers explicitly both model and parameter uncertainties.

\section{SUMMARY}

The SPT-based simplified method recommended in Youd et al. (2001) has been examined for its model uncertainty within the framework of the first order reliability method. Strictly speaking, the model uncertainty determined and presented in this paper is not exactly the model uncertainty of this SPT-based model because several assumptions and adjustments were made in the model calibration process. These included: 1) the Youd et al. (2001) method was modified slightly, as described previously, and the entire limit state model was defined by Eqs. (1) through (10); 2) all input random variables for the calculation of CSR and CRR were assumed to be lognormally distributed; 3 ) reliability analysis was conducted using FORM; 4) correlation between the model uncertainty $c$ and the basic input variables of the limit state model was assumed to be negligible; and 5) non-informative prior regarding sample disparity in the database of case histories, reported by Cetin et al. (2002), was employed. Any error induced from these assumptions/adjustments is eventually reflected in the overall model error (uncertainty) that is calibrated with field observations. In other words, the uncertainties in the component models, and those induced by the adjustments/assumptions made, are lumped into the overall model uncertainty. Thus, the calibrated model bias factor $c$ is for the entire "package", with all these adjustments/assumptions, and not just the model uncertainty of the original Youd et al. (2001) method.

It should be noted that for each case in the database that is used for model calibration, the CSR computed with the peak horizontal ground surface acceleration and the CRR computed based on the SPT blow counts have a noticeable margin of error. In other words, the calibrated model uncertainty may be affected by the uncertainty in the case history data. However, the deterministic model (Youd et al., 2001) that evaluates the liquefaction potential using CSR and CRR is widely accepted, the database of case histories by Cetin et al. (2004) is considered the most updated and accurate by the profession, and the uncertainty in the input parameters in each case in the database is included in the calibration within the framework of the well-accepted first order reliability method (FORM), therefore, the proposed FORM analysis framework developed through this comprehensive calibration process is considered to be satisfactory.

Using the entire calibrated package as a whole, the FORM analysis that considers the variation of the input variables, the correlations among the input variables, and the model uncertainty, as illustrated previously in the EXAMPLE APPLICATION section, can produce a reasonable estimate of the probability of liquefaction, either in liquefied cases or non-liquefied case. The entire process can easily be implemented in a spreadsheet for practical application. Moreover, possible variation of the computed probability of liquefaction can easily be determined with only two additional spreadsheet solutions. The spreadsheet is available from the first author upon request.

\section{CONCLUSIONS}

1. A new procedure has been developed and verified with which the uncertainty of a geotechnical model can be effectively characterized. This procedure involves two steps, (a) deriving a Bayesian mapping function based on a database of case histories, and (b) back-figuring model uncertainty by means of the calibrated Bayesian mapping function. Results of an extensive series of analyses show that this procedure is effective for estimating model uncertainty of an SPT-based model using observed field liquefaction performances. The developed approach is considered innovative as the uncertainty of a semi-empirically established model for liquefaction evaluation can be quantified so that a more realistic reliability analysis can be performed.

2. Regardless of what the prior probability ratio $r$ is used, the effect of the variation of $\mathrm{COV}_{c}$ (coefficient of variation of the model factor $c$ ) on the final nominal probability $P_{\mathrm{L} 3}$ obtained from the FORM analysis is shown to be relatively insignificant. At $r=1$, the mean of the model factor that represents the uncertainty of the modified Youd et al. (2001) model is back-figured to be $\mu_{\mathrm{c}}=0.92$ under the assumption of $\mathrm{COV}_{-\mathrm{c}}=0$; or alternatively with the assumption of $\mathrm{COV}_{-\mathrm{c}}=0.2$ (which is approximately an optimum value), the mean of the model factor is found to be $\mu_{\mathrm{c}}$ $=0.94$. The difference between the $P_{\mathrm{L} 3}$ values calculated with these two statistical characterizations of model factor, in terms of the root-mean-square-error (RMSE) using 201 cases, is quite small (approximately equal to 0.02 ). The assumption of $\mathrm{COV}_{-}=0$ can thus be made for back-figuring $\mu_{\mathrm{c}}$ without incurring much error, as the effect of such assumption appears to have been "compensated" in the calibration of $\mu_{\mathrm{c}}$.

3. The prior probability ratio $r$ is estimated in this paper based on the findings of the comprehensive study of weighting factors that were used to correct the effect of choice-based sampling bias by Cetin et al. (2004). Based on a series of sensitivity analyses using the findings by Cetin et al. (2004), the variable $r$ is characterized with a mean of $\mu_{\mathrm{r}}=0.82$ and a standard deviation of $\sigma_{\mathrm{r}}=0.18$. The assumption of $r=1$ used in the previous study by Juang et al. (2006) and the preliminary analysis in this paper is found to be within one standard deviation of the most probable estimate (mode $=$ $0.85)$ or the mean $\left(\mu_{\mathrm{r}}=0.82\right)$.

4. The mean of the model factor, $\mu_{\mathrm{c}}$, calibrated with observed performances is found to be dependent on the prior probability ratio $r$, as reflected in Eq. (18). Because $r$ is a random variable $\left(\mu_{\mathrm{r}}=0.82, \sigma_{\mathrm{r}}=0.18\right)$, the uncertainty in $r$ will lead to the uncertainty in the 
calibrated $\mu_{\mathrm{c}}$, regardless of the assumption that the coefficient of variation of the model factor $\mathrm{COV}_{-c}=0$. The variation of $\mu_{\mathrm{c}}$, in terms of standard deviation, as a result of the uncertainty in the estimated $r$, is found to be $\sigma_{\mu_{\mathrm{c}}}=0.04$.

5. For a future case, the probability of liquefaction $P_{\mathrm{L}}$ can be determined through a FORM analysis that considers the model uncertainty $\left(\mu_{\mathrm{c}}=\bar{\mu}_{\mathrm{c}}=0.96\right.$ and $\mathrm{COV}_{\mathrm{c}}$ $=0$ inferred at $\left.r=\mu_{\mathrm{r}}=0.82\right)$, the case-specific parameter uncertainties, and the correlations among the input variables. Whereas the $P_{\mathrm{L}}$ determined by the FORM analysis for a given case is a point estimate, the variation in the calculated $P_{\mathrm{L}}$ can be caused by the uncertainty in the estimated model factor. Equations (23) and (24) provide a means for an estimate of the variation in the calculated $P_{\mathrm{L}}$, in terms of standard deviation, caused by the uncertainty in the estimated model factor.

6. Example application of the FORM analysis with the calibrated model factor presented in this paper shows that the procedure is easy to apply, particular with a spreadsheet solution. This is encouraging as the procedure also has a sound theoretical basis. This procedure may be used for evaluating the probability of liquefaction in a routine practice. Further validation of the developed procedure using additional ground performance data, however, is desirable. Additional comparison with existing probabilistic models using more ground performance data should also be made.

7. Using the entire package as a whole, the FORM analysis that considers the variation of the input variables, the correlations among the input variables, and the model uncertainty can produce reasonable estimates of the probability of liquefaction, either in liquefied cases or non-liquefied cases. Thus, the results presented in this paper have extended the use of the Youd et al. (2001) method from being a deterministic model to being capable of providing both deterministic and probabilistic solutions.

\section{ACKNOWLEDGEMENT}

The study on which this paper is based was supported by the National Science Foundation through Grant CMS-0218365 under program director Dr. Richard J. Fragaszy. This financial support is greatly appreciated. The opinions expressed in this paper do not necessarily reflect the view and policies of the National Science Foundation. The third and last authors appreciate the financial support in part by the Research Grant Council of Hong Kong through Grant No. HKUST 620206. Dr. Kemal Onder Cetin of Middle East Technical University, Turkey, is thanked for providing his database of case histories.

\section{REFERENCES}

1) Ang, A. H.-S. and Tang, W. H. (1984): Probability Concepts in Engineering Planning and Design, Vol. II: Design, Risk and Relia- bility, John Wiley \& Sons, New York.

2) Baecher, G. B. and Christian, J. T. (2003): Reliability and Statistics in Geotechnical Engineering, John Wiley \& Sons, New York.

3) Cetin, K. O. (2000): Reliability-based assessment of seismic soil liquefaction initiation hazard, Ph.D. Dissertation, University of California, Berkeley, CA.

4) Cetin, K. O., Der Kiureghian, A. and Seed, R. B. (2002): Probabilistic models for the initiation of seismic soil liquefaction, Struct. Safety, 24(1), 67-82.

5) Cetin, K. O., Seed, R. B., Der Kiureghian, A., Tokimatsu, K., Harder, L. F., Jr., Kayen, R. E. and Moss, R. E. S. (2004): Standard penetration test-based probabilistic and deterministic assessment of seismic soil liquefaction potential, Journal of Geotechnical and Geoenvironmental Engineering, ASCE, 130(12), 1314-1340.

6) Christian, J. T. and Swiger, W. F. (1975): Statistics of liquefaction and SPT results, Journal of Geotechnical Engineering, ASCE, 101(11), 1135-1150.

7) Der Kiureghian, A. and Lin, P. L. (1985): Structural reliability under incomplete probability information, Research Report No. $U C B / S E S M-85-01$, Univ. of California, Berkeley, CA.

8) Duncan, J. M. (2000): Factors of safety and reliability in geotechnical engineering, Journal of Geotechnical and Geoenvironmental Engineering, ASCE, 126(4), 307-316.

9) Frankel, A. D., Petersen, M. D., Mueller, C. S., Haller, K. M., Wheeler, R. L., Leyendecker, E. V., Wesson, R. L., Harmsen, S. C., Cramer, C. H., Perkins, D. M. and Rukstales, K. S. (2002): Documentation for the 2002 Updated of the National Seismic Hazard Maps, U.S. Geol. Surv. Open-File Rept. 02-420.

10) Gutierrez, M., Duncan, J. M., Woods, C. and Eddy, E. (2003): Development of a simplified reliability-based method for liquefaction evaluation, Final Technical Report, USGS Grant No. 02HQGR0058, Virginia Polytechnic Institute and State Univ., Blacksburg, VA.

11) Haldar, A. and Tang, W. H. (1979): Probabilistic evaluation of liquefaction potential, Journal of Geotechnical Engineering, ASCE, 104(2), 145-162.

12) Haldar, A. and Mahadevan, S. (2000): Probability, Reliability and Statistical Methods in Engineering Design, John Wiley \& Sons, New York.

13) Harr, M. E. (1987): Reliability-Based Design in Civil Engineering, New York: McGraw-Hill.

14) Hassan, A. M. and Wolff, T. F. (1999): Search algorithm for minimum reliability index of earth slopes, Journal of Geotechnical and Geoenvironmental Engineering, ASCE, 125(4), 301-308.

15) Idriss, I. M., Arango, I. and Brogan, G. (1979): Study of liquefaction in November 23, 1977 Earthquake San Juan Province, Argentina, Final Report, Woodward-Clyde Consultants, California.

16) Iwasaki, T., Tatsuoka, F., Tokida, K. I. and Yasuda, S. (1978): A practical method for assessing soil liquefaction potential based on case studies at various sites in Japan, Proc. 2nd Int. Conf. on Microzonation for Safer Construction-Research and Application, II, San Francisco, 885-896.

17) Jefferies, M. G., Rogers, B. T., Griffin, K. M. and Been, K. (1988): Characterization of sandfills with the cone penetration test, Penetration Testing in the UK, Thomas Telford, London, UK, 199-202.

18) Juang, C. H., Rosowsky, D. V. and Tang, W. H. (1999): Reliability-based method for assessing liquefaction potential of soils, Journal of Geotechnical and Geoenvironmental Engineering, ASCE, 125(8), 684-689.

19) Juang, C. H., Chen, C. J., Rosowsky, D. V. and Tang, W. H. (2000): CPT-based liquefaction analysis, Part 2: Reliability for design, Géotechnique, 50(5), 593-599.

20) Juang, C. H., Jiang, T. and Andrus, R. D. (2002): Assessing probability-based methods for liquefaction evaluation, Journal of Geotechnical and Geoenvironmental Engineering, ASCE, 128(7), 580-589.

21) Juang, C. H., Yang, S. H., Yuan, H. and Khor, E. H. (2004): Characterization of the uncertainty of the Robertson and Wride model for liquefaction potential, Soil Dynamics and Earthquake 
Engineering, 24(9-10), 771-780.

22) Juang, C. H., Fang, S. Y. and Khor, E. H. (2006): First-order reliability method for probabilistic liquefaction triggering analysis using CPT, Journal of Geotechnical and Geoenvironmental Engineering, ASCE, 132(3), 337-350.

23) Juang, C. H., Li, K., Fang, Y., Liu, Z. and Khor, E. H. (2008a): Simplified procedure for developing joint distribution of $a_{\max }$ and $M_{\mathrm{w}}$ for probabilistic liquefaction hazard analysis, Journal of Geotechnical and Geoenvironmental Engineering, 134(8), 1050-1058.

24) Juang, C. H., Fang, S. Y. and Li, D. K. (2008b): Reliability analysis of liquefaction potential of soils using standard penetration test, Chapter 13, Reliability-Based Design in Geotechnical Engineering-Computations and Applications (ed. by Kok-Kwang Phoon), Taylor \& Francis, London, U.K.

25) Kramer, S. L. and Mayfield, R. T. (2007): Return period of soil liquefaction, Journal of Geotechnical and Geoenvironmental Engineering, ASCE, 133(7), 802-813.

26) Liao, S. S. C., Veneziano, D. and Whitman, R. V. (1988): Regression model for evaluating liquefaction probability, Journal of Geotechnical Engineering, ASCE, 114(4), 389-410.

27) Low, B. K. and Tang, W. H. (1997): Efficient reliability evaluation using spreadsheet, Journal of Engineering Mechanics, ASCE, 123(7), 749-752.

28) NEHRP (1998): NEHRP Recommended Provisions for Seismic Regulations for New Buildings and Other Structures, Part 1-Provisions: FEMA 302, Part 2-Commentary FEMA 303, Federal Emergency Management Agency, Washington DC.

29) Phoon, K. K. and Kulhawy, F. H. (1999): Characterization of geotechnical variability, Canada Geotechnical Journal, 36, 612-24.

30) Phoon, K. K. (2004): General non-gaussian probability models for first order reliability method (FORM): A state-of-the Art Report, ICG Report 2004-2-4 (NGI Report 20031091-4), International Center for Geohazards, Oslo, Norway.

31) Phoon, K. K. and Kulhawy, F. H. (2005): Characterization of model uncertainties for laterally loaded rigid drilled shafts, Géotechnique, 55(1), 45-54.

32) Phoon, K. K., Chen, J. R. and Kulhawy, F. H. (2006): Characterization of model uncertainties for augered cast-in-place (ACIP) piles under axial compression, Foundation Analysis \& Design: Innovative Methods, Geotechnical Special Publication, ASCE, Reston, VA, 153, 82-89.

33) Seed, H. B. and Idriss, I. M. (1971): Simplified procedure for eval- uating soil liquefaction potential, Journal of the Soil Mechanics and Foundation Div., ASCE, 97(9), 1249-1273.

34) Seed, H. B., Tokimatsu, K., Harder, L. F. and Chung, R. (1985): Influence of SPT procedures in soil liquefaction resistance evaluations, Journal of Geotechnical Engineering, ASCE, 111(12), 1425-1445.

35) Stewart, J. P., Liu, A. H. and Choi, Y. (2003): Amplification factors for spectral acceleration in tectonically active regions, Bulletin of Seismological Society of America, 93(1), 332-352.

36) Tohno, I. and Yasuda, S. (1981): Liquefaction of the ground during the 1978 Miyagiken-Oki earthquake, Soils and Foundations, 21(3), 18-34.

37) Toprak, S., Holzer, T. L., Bennett, M. J. and Tinsley, J. C., III (1999): CPT- and SPT-based probabilistic assessment of liquefaction, Proc. 7th US-Japan Workshop on Earthquake Resistant Design of Lifeline Facilities and Countermeasures Against Liquefaction, Seattle, August 1999, Multidisciplinary Center for Earthquake Engineering Research, Buffalo, NY, 69-86.

38) United States Geological Survey (USGS) (2002a): National Seismic Hazard Maps website, (http://earthquake.usgs.gov/research/ hazmaps).

39) United States Geological Survey (USGS) (2002b): National Seismic Hazard Maps website for de-aggregation, (http://eqint.cr.usgs. gov/eq-men/html/deaggint2002-06.html).

40) Yang, S. H. (2003): Reliability analysis of soil liquefaction using in situ tests, Ph.D. Dissertation, Clemson University, Clemson, South Carolina.

41) Youd, T. L. and Noble, S. K. (1997): Liquefaction criteria based on statistical and probabilistic analyses, Proc. NCEER Workshop on Evaluation of Liquefaction Resistance of Soils, Technical Report NCEER-97-0022, (eds. by T. L. Youd and I M. Idriss), National Center for Earthquake Engineering Research, State University of New York at Buffalo, Buffalo, NY, 201-215.

42) Youd, T. L., Idriss, I. M., Andrus, R. D., Arango, I., Castro, G., Christian, J. T., Dobry, R., Liam Finn, W. D., Harder, L.F., Jr., Hynes, M. E., Ishihara, K., Koester, J. P., Laio, S. S. C., Marcuson, W. F., III, Martin, G. R., Mitchell, J. K., Moriwaki, Y., Power, M. S., Robertson, P. K., Seed, R. B. and Stokoe, K. H., II. (2001): Liquefaction resistance of soils: summary report from the 1996 NCEER and 1998 NCEER/NSF workshops on evaluation of liquefaction resistance of soils, Journal of Geotechnical and Geoenvironmental Engineering, ASCE, 127(10), 817-833. 